Portland State University

PDXScholar

$1-1-2010$

\title{
Working Mothers' Decisions, Experiences and Feelings about using On-Site Childcare
}

Stephanie LaRae Hixson-Somanchi

Portland State University

Follow this and additional works at: https://pdxscholar.library.pdx.edu/open_access_etds Let us know how access to this document benefits you.

\section{Recommended Citation}

Hixson-Somanchi, Stephanie LaRae, "Working Mothers' Decisions, Experiences and Feelings about using On-Site Childcare" (2010). Dissertations and Theses. Paper 19.

https://doi.org/10.15760/etd.19

This Dissertation is brought to you for free and open access. It has been accepted for inclusion in Dissertations and Theses by an authorized administrator of PDXScholar. Please contact us if we can make this document more accessible: pdxscholar@pdx.edu. 
Working Mothers' Decisions, Experiences and Feelings about using On-Site Childcare

by

Stephanie LaRae Hixson-Somanchi

A dissertation submitted in partial fulfillment of the requirements for the degree of

\author{
Doctor of Philosophy \\ in \\ Urban Studies
}

\author{
Dissertation Committee: \\ Carl Abbott, Chair \\ Earl Molander \\ Loren Lutzenhiser \\ Hollie Lund \\ Melissa Thompson
}

Portland State University

(C) 2010 


\begin{abstract}
On-site childcare is an ever-increasing form of childcare. By understanding the decisions, experiences and feelings of mothers using on-site centers, informed policy decisions about viable childcare models can be made.

In the broadest terms current literature reveals that economic, societal, functional, and psychological factors influence a mother's decisions in regards to using childcare. This study used these markers as the basis for the development of questions to ascertain the experiences, feelings and decisions of mothers using on-site childcare.

A phenomenological method was used. Twenty-four participants using on-site childcare from four organizations in different industries were located through a snowball sample for in-depth interviews. The interviews were audio-recorded, transcribed, and coded to derive themes of experiences.
\end{abstract}

The findings reveal that on-site childcare impacts previously described effects of childcare. The factors of primary influence are child proximity and organizational support.

The influence of close proximity can be seen in the themes of Networking, Organizational System Oneness, Family/Community Perception, Mothering Style, Center Quality, Work Time, Commuting Time, Nursing/Lactation, Guilt, Stress Management, and Employee Loyalty.

Organizational assistance and support impact and overlap with proximity as a primary theme source. This can be seen in the themes of Cost, Networking, Organizational System Oneness, Waiting List, Center Quality, Work Time, Commuting 
Time, Nursing/Lactation, Stress Management and Employee Loyalty. The quality of the childcare, which in large part is made possible by the supporting organization, is held in such high regard that in some cases it overcomes the mother's desire for proximity. The implications of these findings are that high quality on-site childcare provides a significant benefit for mothers, organizations and communities. Family friendly organizational policy and feminist urban planning methods are better informed. 


\section{Dedication}

To: Arvid Dean Hixson

My father and educational inspiration 


\section{Acknowledgements}

I was beyond fortunate to have the support of my husband, Dr. SubbaRao Somanchi, throughout this process. He encouraged me, believed in me, listened to me cry and complain, and as if that were not enough he proof-read nearly every written word over the four years of my doctoral program. I can only hope that some of his genius mind has seeped into me over the course of our marriage. Certainly his patience, love and support have provided an invaluable foundation for my growth.

My father's love of education and intelligence planted the seed of desire for this degree in me while in high school. To reach the highest level of education seemed to provide an incredible form of validation. Knowing I was in a doctoral program gave my father great pride. He battled and lost his struggle with brain cancer while I advanced through my studies. I hold his lessons and pains close as I continue our family evolution. What this degree has brought me is actually a sense of closure and understanding that the degree could never create worth. I have always been worthy and from this worth I have this accomplishment. Daddy, I believe I have slain the demon of misunderstanding, the meaning and value of a title, for both of us.

The eternal optimism and cheer of my mother, Sherry Hixson, fostered in me the belief that nothing was impossible. The core of her life has centered around the Stoddard quote, "Bread and water can so easily be toast and tea." The belief that one simply moves daily towards one's best and that nothing is impossible has benefited me in ways I continue to discover. Her energy and cheer are my inspiration and never fail to lift me. I extend to her my deepest gratitude for the success she has fostered. 
It was a moment of great fortune when Dr. Carl Abbott agreed to chair my dissertation committee. He has the rare combination of being both brilliant and practical. His organization and response time are simply profound. And, surely his patience is saintly. His guidance and support through the dissertation have allowed me to produce research that sheds light on this important societal issue. 


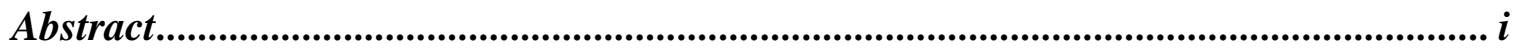

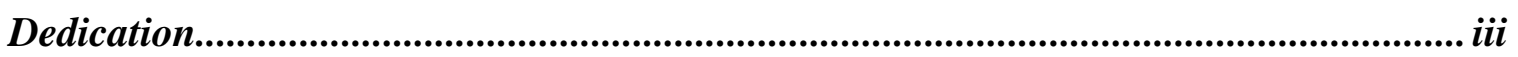

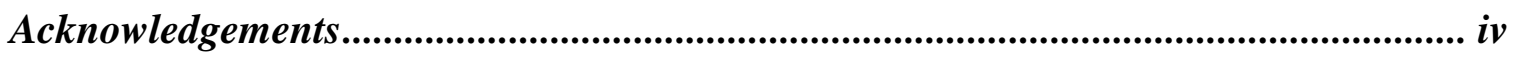

Chapter 1 Problem Introduction ............................................................................. 1

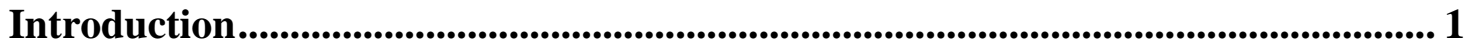

Research Context ........................................................................................................ 1

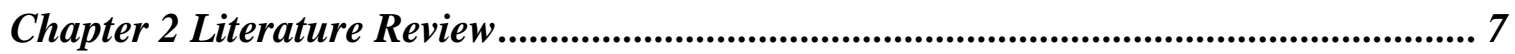

Literature Review / Contextual Framework ........................................................................... 7

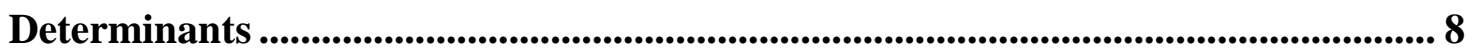

Literature Review / Contextual Framework Summary ......................................... 14

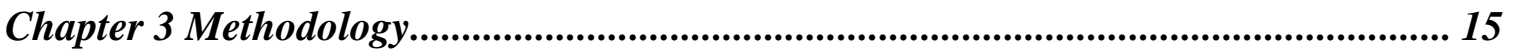

Chapter 3 Methodology.................................................................................................... 15

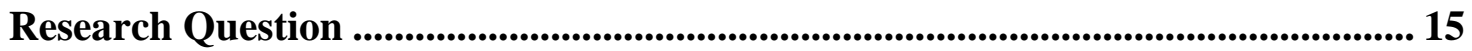

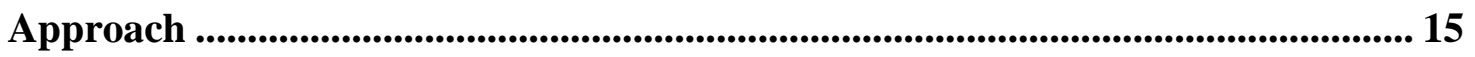

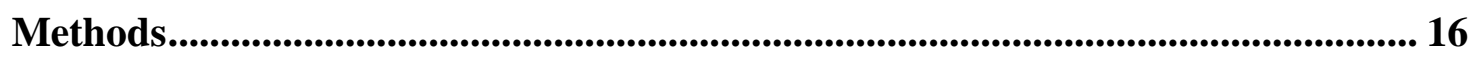

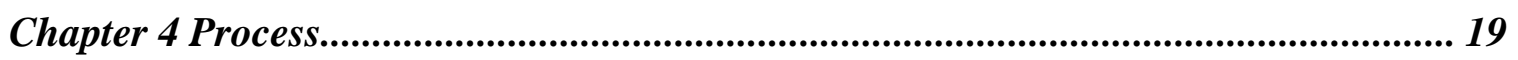

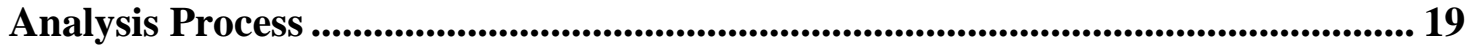

Research Sites \& Participants Structure ................................................................... 20

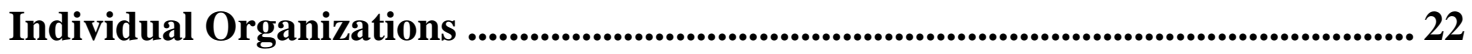

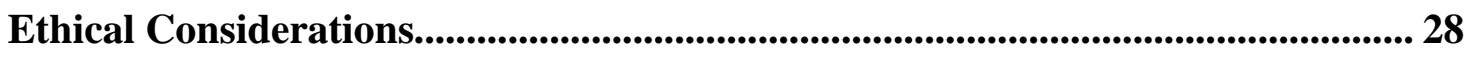

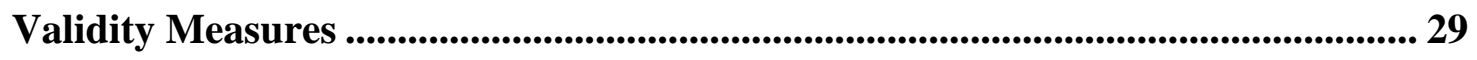

Chapter 5 Institutional Context Results ..................................................................... 33

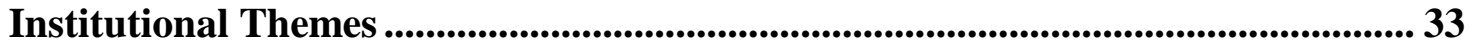

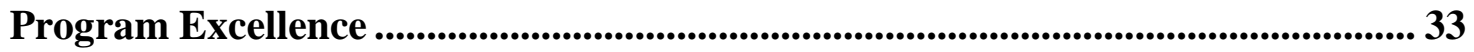

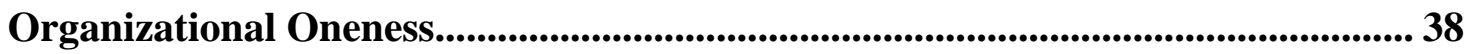

Segmented vs. Integrated Organizational Cultures.................................................... 41

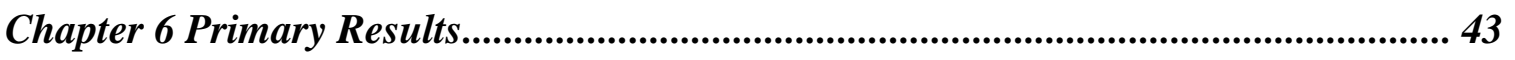

Participant Context......................................................................................................................... 43

Theme Analysis ............................................................................................................................ 44

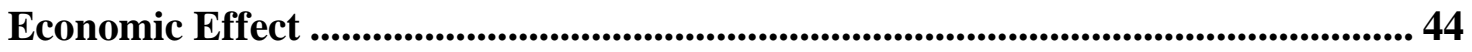


Societal Effect ....................................................................................................................... 46

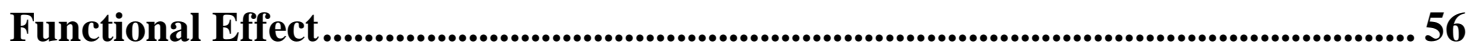

Psychological Effect ............................................................................................................ 65

Chapter 7 Conclusions..................................................................................................... 72

Research Summary .................................................................................................................. 72

Policy Suggestions ................................................................................................................... 81

Suggested Future Research ................................................................................................. 83

Feminist Urban Planning \& Feminist Organizational Behavior............................... 85

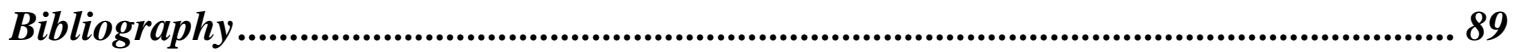

Appendix A - On-Site Directors Interview Questions ....................................................... 93

Appendix B - Teachers/Caretakers Interview Questions................................................ 94

Appendix C - Mothers Interview Questions ..................................................................... 95

Appendix D - Analysis Example ........................................................................................ 97

Appendix E - Analysis Process Diagram......................................................................... 98

Appendix F - Human Subjects Review Application .......................................................... 99 


\section{Chapter 1 Problem Introduction}

\section{Introduction}

In order for women to remain employed and economically stable, access to childcare is paramount. Quality childcare is necessary for the prevention and reduction of poverty. Strategies that benefit this need, such as on-site childcare, may be a part of effective feminist urban planning and serve to increase city livability. This study examines working mothers' decisions, experiences and feelings about using on-site childcare. Knowledge of this contributes a significant piece to understanding the broader vision of meeting mothers' needs in organizations and society. It also plays an important role in informing urban design, government policy, and organizational structures while informing the direction of future childcare research.

Organizations that provide on-site childcare may reveal ideas or models that can be used in more organizations or provide viable concept for government sponsorship. Without a broader understanding as to how types of childcare options affect women, the best decisions for urban planning and organizational planning cannot be realized. This study explores the effects of on-site childcare on working mothers' decisions and feelings.

\section{Research Context}

\section{On-Site Childcare}

It is reported that although one tenth of one percent of all American-based companies offer on-site childcare, the number is growing by 35 percent per year. According to Linda Mason the President of Bright Horizons Family Solutions, a 
childcare consulting service, the cost to organizations is relatively small. Although onsite childcare centers are rare they are an expanding form of childcare.

Early studies reveal that on-site childcare is an incentive to employees. Organizations often offer on-site childcare as an effective incentive to bring in quality employees and have an increased rate of employee retention. It is noted that a top reason for the longevity is an ability to balance work and family (Levin-Epstein, 2001). In addition, on-site childcare is an increasingly important tool to keep and attract employees because it is often seen as an amenity or part of a bonus package (Fleischer, 1995). Also, on-site childcare centers are seen as an emerging benefit that marks organizations looking for ways to meet the needs of their employees, as well as establish a family-employeefriendly work atmosphere.

It is such an important draw, that it was found that more than fifty percent of employees reported that they would be willing to help fund an on-site childcare program when asked: "If everyone in your company were asked to contribute a percentage of their income to provide onsite daycare at your place of work, would you be willing to give a percentage of your income for this purpose?" This finding held true across age and gender demographics (Frazee, 1996).

This form of funding would act as a tax on all employees. On average, employees were willing to contribute four percent of their salaries for the childcare program (Frazee, 1996). This demonstrates that the demand for on-site daycare may be quite high because employees across demographics, including those not utilizing the service, are willing to contribute their own salaries in order to offer on-site childcare. This is an important 
finding because it indicates that if this model is found to be effective it may increase both the number and types of organizations that implement on-site childcare programs.

European studies also show strong evidence that on-site childcare allows women to remain in the workplace. On-site childcare is considerably more prominent in Western European countries, specifically Sweden and Denmark, than in the United States (Hjern, Haglund, Rasmussen, \& Rosen, 2000). This is likely due to the fact that these centers are more often subsidized by the company or the government in Europe.

The literature also addresses the need for quality childcare in domestic welfare reform. One study found that without access and subsidies to childcare, the success of welfare to work programs are limited (Meyers, 1997). Research discusses the burden that the cost of childcare can place on a family, and the limited access to quality childcare in

disadvantaged neighborhoods (Lifton, 2001). These studies underscore the importance of access to childcare in order to break the cycle of poverty. While on-site childcare does not currently target disadvantaged people and situations, a better understanding of the effects of on-site childcare on working women may prove a valuable information source as new childcare services options are considered to improve child care services for all demographics.

\section{Organizational Considerations / Working Mothers}

Nearly every organization will employ women who are or will become mothers. An estimated sixty percent of women with children less than one year of age are working at least part time, making it clear that there is a need to address this substantial portion of society and its ability to be productive (Pungello \& Kurtz-Costes, 2000). How to retain and positively impact productivity of women with offspring is thus an important 
consideration for organizations, and the development of policies that address the needs of working mothers is of paramount concern for the well being of both working mothers and organizations. Finding ways to retain women after childbirth in positions that fully utilize their experience and education provides economic benefits to the employer, employee and the economy as a whole (Millward, 2006).

However, the increase of women the workplace, and the lack of shifts in household and family responsibilities, is limiting the types, qualities, experiences, and opportunities for career advancement for women (Shainees, 1980; Baker, 1992). Women's entrance into the labor market has exacerbated incompatibilities between employers and family interests. In many ways this is due to the conflict between paid work and family responsibilities. This conflict is linked to both decreased employee productivity and decreased family functioning (Glass \& Estes, 1997). Through an understanding of work-family incompatibilities, societal policies can be developed that ease the tension. This knowledge also empowers organizations to foster workplace atmospheres that are mutually beneficial to women and organizational objectives.

\section{Family Friendly Policies}

Beneficial policies that recognize an employee's need to balance life outside of work have come to the attention of organizations and are part of an employee's preference toward organizations. In order to obtain and retain the best employees, organizations have become increasingly motivated to address policies that increase worklife effectiveness. These policies are often referred to as "family friendly". Organizations that implement family friendly programs find that in return employees have positive attitudes and display behaviors of appreciative employees (Swoody, 2007). 
Family friendly policies may include assistance with childcare, education programs, lactation programs, and support systems (Cardenas, 2005; Glass \& Riley, 1998). Often these policies have a significant impact on working mothers. Decisions on implementing the most effective family friendly polices must be based on an understanding of the needs and concerns of the organization's employees.

\section{Adoption of Family Friendly Policies}

Organizations may adopt family friendly policies for a variety of reasons. In some cases the motivation resides in creating an image for the organization. An image that touts family friendly policies may attract the best employees and may also receive recognition in the press for the progressive policies (Blair-Loy \& Wharton, 2002). However, despite the policies listed through human resource centers, companies go through stages of implementing family friendly policies within the organization. An organization may be in a "passive toleration" stage that meets the bare minimum of legal requirement and makes little attempt to assist employees in using family friendly policies or assist in offering family friendly policies that exceed minimum standards. The intermediate stage for organizations is "reluctant opening," where an organization may offer family friendly policies beyond the legal requirement, but offer little assistance in aiding employees in the use of such policies. Use of the policies may even be discouraged. Family friendly policies are prominently utilized in organizations that are in “active formation." At this stage, an organization vigorously seeks to implement family friendly policies that are well beyond the legal statues and fosters an environment that encourages the use of such polices (Bagihole, 2006).

\section{Contribution of Study}


This study addresses one type of family friendly organizational policy, on-site childcare. Knowledge about working mothers' decisions and feelings about using on-site childcare contributes a significant piece to understanding the broader vision of meeting mothers' needs in organizations and society. The study can play an important role in informing urban design, government policy, and organizational structures. It can also inform the direction of future childcare research.

\section{Feminist Organization Theory}

The measurement of success for family friendly policies that are based on the decision making determinants of mothers should be weighed against the perspectives offered by feminist organizational theory (Mahitivanichcha \& Rorrer, 2006). Currently there is a gendered masculine bias in regards to what constitutes rationality. Feminist measures emphasize concepts of responsibility, obligation and care rather than rights, rules and justice which have been the predominate form of male thought (Morgen, 1990). Feminist organizational theories are measured against the masculine system of rationale, causing feminist theories to remain isolated as a sub-sect of study. In order for advances in feminist issues to occur, both forms of rationality must be brought together for discussion (Ross-Smith \& Kornberger, 2004). This would bring a balance between notions of care and concepts of justice, which makes a case for discussion of topics by utilizing inclusive, consensus approaches (Hendler, 1994). Utilizing these theories will aid in the success of family friendly policies and should be weighed in the interpretation of the results of this research. 


\section{Chapter 2 Literature Review}

\section{Literature Review / Contextual Framework}

The framework of this study, to understand the decisions experiences and feelings of working mothers utilizing on-site childcare programs, begins with a literature review examining what is known in regards to the broader understanding of women's decision to return to work after childbirth. It is a complex decision that is made based on a number of variables. Understanding these variables and the history that influenced them allowed for an informed study design and a base of knowledge to develop questions that answer how on-site childcare affects what is currently understood in regard to women's childcare decisions. It also provides a context for understanding the experience and feelings of women using on-site centers.

\section{Historical Reference}

The history of childcare provides a context for analysis. Evolving social situations have led to the creation of childcare options. Although childcare has been necessary for centuries, it has only been since middle and upper class women have demanded such options that the spread of childcare centers has become available. There has been a long social dictate in American culture against the use of childcare centers, and these attitudes are an influence today (Durst, 2005). At the turn of the century, promoted family values dictated that mothers stay home to care for children, and the use of child care services were only offered through charity organizations that determined “deserving" families. However, as time progressed holding these restrictions on childcare use in the working population became difficult. Working women began to 
challenge the system and demand parental rights in childcare centers. Nevertheless, the legacy of childcare evolution affects the choices many women are making today about returning to the workforce and childcare options.

\section{Determinants}

The current literature reveals four categories of factors considered by mothers in making the decision to return to the workplace: economic, societal, functional, and psychological.

\section{Economic}

Financial need is stated repeatedly as a reason to utilize childcare and return to the workforce (Robinson, Rotter \&Wilson, 1982). The realities of household expenses are a clear concern in the decision making process. For some women this factor is the sole deciding measure in choosing to return to the workforce and place children in childcare. In some cases the mother is divorced, single, or separated and the mother's income is the only income source. In other cases, the need for dual income is necessary to the family. Studies reveal that children who are placed in childcare at three months or before tend to come from economically disadvantaged households. After three months, purchased childcare tended to indicate economically advantaged households (Sylva, Stein, Leach, Barnes \& Malmberg, 2007).

Another prominent economic concern is in regards to the effects of career interruption (Glass \& Riley 1998). The career loss that may be suffered for a time gap in the workplace may significantly alter a woman's earning capacity as well as alter career building opportunities. Fears over losing employment completely, if extended leave is 
taken, are serious economic concerns that are considered by women (Leach, Barnes, Nichols, Goldin, Stein, Sylva \& Malmberg 2006).

Economic stability is stipulated as a decision making factor for working mothers. The realities of the divorce rate, and desire to retain financial equity within a marriage are cited as reasons to remain in the workforce. The assurance of economic viability for women acts as an insurance of stability, and the retention of equitable economic decision making within partnerships. It limits situations of dependency, and maintains options that provide for clear decision making (Robinson, Rotter \& Wilson, 1982).

The cost of childcare is a key factor in deciding to return to the workplace (Powell, 2002). Many mothers cite that although they would like to return to work the cost of childcare is not cost-effective in a move towards that decision. In some cases childcare is more expensive than the wages being earned by the mother. In other cases the marginal benefits are not deemed adequate for returning to work. This concern is also taken into consideration with career interruption. Although some women find that the cost of childcare negates their salary, a decision to remain in the workforce is made in expectation that career development will bring greater benefit over the earning time span of the woman.

\section{Societal}

The support that a mother receives holds a significant bearing on her decision to return to the workplace. Family responsive workplaces are influential factors in a mother remaining employed with an organization. Lactation programs, child care options, parental education programs, and workplace structures are examples of the support systems that can be helpful to working mothers (Cardenas, 2005). Employers are 
realizing that providing these benefits can help to retain valued employees, reduce turnover, and in many cases are economically beneficial to the organization due to increased employee productivity (Gault \& Lovell, 2006). Lowering the conflicts between paid work and family responsibility is a concern that is becoming more prominent to organizations as women make decisions about employment based on the support provided by the workplace (Glass\& Estes, 1997).

Support within the home is also a factor in the employment decisions of mothers. Women often maintain traditional home duties, even when taking on employment roles. While there have been shifts in the image of women working, the traditional motherhood roles have lagged in the evolution of women's roles (Shainees, 1980). This has led to an overburdening of women trying to manage the dual role of employee and mother. The support of husbands in the duties of the home plays a significant role in the ability of the woman to manage employment duties (Edwards, 2006). Extended family support may also hold a role in lessening the burdens on mothers and allowing for women to return to the workplace. The support of friends and community is another factor of support to be considered in the reasoning of working mothers' decisions.

The quality of the experience in the workplace is a consideration for working women. Finding jobs that are sensitive to the experiences of working mothers have led many women to look to fields that are female-dominated for employment (Stier, 1996). While some employers may hold and support policies that are a draw for women, if the connective environment within the organization does not create a quality experience for working mothers, women tend to abandon these jobs when mothers. Stier believes that this has led to the "ghettoization" of women's employment roles. What is understood is 
that the comfort and the expressed quality of the work environment plays a factor in mother's choosing to remain employed with the organization.

Societal belief patterns regarding the role of mothers are a prime determinant in the decision mothers make to return to work and use childcare. Durst's (2005) explanation about the origins and evolution of childcare provide a context for understanding some of the negative associations around the choice to use childcare, as well as help to explain how as women have increasingly demanded childcare other opinions have formed. Depending on the social influence group a mother is originating in, she can have positive or negative associations with using childcare and being a working mother (Glass \& Riley, 1998). A mother's social circle and family can also have an influence on the opinion a woman holds about placing her child in care and returning to work (Pungello\& Kurtz-Costes, 2000). If there is a consensus within the social group that returning to work is an empowering or a necessary act, and consensus that children thrive in childcare, these factors will tend to influence a mother towards the choice of utilizing childcare. Strongly held opinions by the mother's community that women should be home with their children or a belief that childcare is destructive to children, has a tremendous impact on the mother's decision making process towards avoiding childcare.

Employment or remaining home can also hold a form of status among different groups (Shainees, 1980). Some women see their jobs as a status symbol of being educated and well off. A job may hold more meaning for some mothers than employment; it may be a necessary measure to fit into desired social circles to indicate status, wealth, or education (Robinson, Rotter \& Wilson, 1982). In other social circles 
staying home with children is seen as living well, or coming from a position of financial comfort.

\section{Functional}

Despite the importance of intangible qualities, several other factors come into consideration for women choosing to return to work following childbirth. Work flexibility is paramount in maintaining employment (Cardenas, 2005) (Pungello \& KurtzCostes, 2000). Women require flexibility to meet the needs of their children and effectively accomplish the tasks of the workplace. Another prime consideration when looking at employment is the assurance that overtime work will be limited (Glass, \& Riley, 1998). Pressure from organizations to work beyond specified hours or to travel often limit the number of women who believe that these jobs are conducive to their role as working mothers (Stier, 1996).

The characteristics of the child also play a role in the decision of women to return to the workplace. The age of the child is important. As research by Sylva, Stein, Leach, Barnes and Malmberg (2007) reveals, this can indicate economic state. Many women feel more comfortable placing a toddler in childcare rather than a newborn infant. In addition to the concerns over age, mothers make decisions about returning to work based on the special needs of the child. If there are developmental concerns, a difficult disposition of the child, or other concerns, a mother is less likely to place her child in outside care and return to the workplace (Pungello, \& Kurtz-Costes, 2000).

\section{Psychological}

Self-perception is crucial to the decision mothers make in returning to the workplace. Many women see a connection between possessing many life roles and their 
identity. Being able to come to a cocktail party and state their profession as well as their role as a mother allows women to wear many hats and hold on to the idea of "having it all". In other cases holding many roles is seen as placing the child in a second-class role and is looked down upon. The mother's self-perception that one would remain employed and use childcare is an important consideration (Robinson, Rotter \& Wilson, 1982).

Holding on to traditional roles of a mother's duties with a home is an important factor. Although this is influenced by societal pressures, a woman's own psychological connection with traditional roles is also a factor and may be more important than the belief patterns of those within her community (Glass, \& Riley, 1998). Due to often conflicting feelings of maintaining a traditional role in the home a mother may feel guilt about her decision to utilize childcare while she is working (Guendouzi, 2006).

In some cases the decision of a mother to return to work is dependent on her preference for the enjoyment that either employment outside the home or the satisfaction of being a stay at home mother brings. The level of satisfaction is a primary decision making factor (Leach, Barnes, Nichols, Goldin, Stein, Sylva \& Malmberg, 2006).

There is also a concern over maintaining out-of-the-home connections. Some mothers feel that by remaining in the home as a mother they will lose touch with the mainstream environment. The fear of losing touch with adult topics, maintaining adult conversations, and remaining a sharp and active adult drives many women to remain employed and utilize childcare options (Robinson \& Wilson, 1982). Another aspect of this is that some mothers feel that by remaining in the workplace they have equalized the relationship status with their husbands/partners. Although this can be an economic 
equality, it also is an important psychological factor for many working mothers in their belief that their outside work creates equality of voice in their relationships.

The choice for childcare seems to be made with the first child. If a mother decides to use childcare with her first child this tends to continue with subsequent children. The reverse is true as well, mothers choosing to remain at home with their children are unlikely to return to the workplace and utilize childcare if they did not with their firstborn child. One reason for this may be that once a decision has been made to use childcare or not a mother will limit cognitive dissonance by reinforcing her decision with positive correlations and negating negative aspects. Despite the choice made, a mother will often be happy with the decision months later even if there was initial indecision (Pungello \& Kurtz-Costes, 2000).

\section{Literature Review / Contextual Framework Summary}

The primary determinants in the decision of women returning to work are: economic, societal, functional, and psychological. These broad categories are influenced by the history of childcare, which impacts attitudes and philosophies of women's roles. However, the literature does not yet address the experiences and decisions of working mothers' utilizing a particular form of childcare, such as on-site, and the resulting impact it may hold on decision making factors. This research fills a gap in the knowledge base with regards to one form of childcare, on-site, as well as provides context by lending information on the feelings and experiences of these mothers. 


\section{Chapter 3 Methodology}

\section{Research Question}

How does on-site childcare influence the experience, decisions and feelings of

working mothers? This is the primary question of the research. From the basis of this question all of the research design originates. The study has also allowed for an emergent design that expands to include answers to additional questions that the research surfaced.

\section{Approach}

Phenomenological methodology was utilized to answer this research question. While other forms of research may provide valuable lenses to understand mothers using on-site childcare, phenomenology allowed the research to expose the experience of the mothers which is essential for providing feedback as to how mothers feel about the system and feel about their decisions. Previous studies have looked at the tangible aspects of on-site childcare, but unless there is a fresh understanding as to how women using the centers feel and experience them, it will remain unknown whether or in what ways on-site childcare is an effective model. This understanding of experience, feelings, and common effects of on-site childcare experienced by mothers expands the known picture of on-site childcare and serves as a basis to explore what could be done to improve the system. Information in this form is also beneficial to policymakers who are determining effective feminist urban planning models, and it may influence organizational systems to rise to the needs of the workforce.

In terms of method structure phenomenology informs this study by allowing multiple people to express their lived experience, which is then summarized to express 
the essence of the common experience of mothers using on-site childcare in this study. Understanding the shared experience is particularly vital in terms of wide-reaching policy decisions. Additionally, phenomenology is consistent with the goals of this research because it asks the researcher to suspend judgment, in regards to the current thoughts on the situation. This is particularly important because the media have tended to frame onsite childcare as a positive model that is meeting the needs of women and families in the workplace. It is generally held in high regard in mass-media publications. ${ }^{1}$ These outlets, while well-meaning, do not provide the objective reasoning that is accomplished through academic reporting methods. In order to have impartial, unbiased understanding of the experience an academic study is necessary. A richer, independent understanding of the experiences of mothers using the centers is exposed in the results.

\section{Methods}

This study uses a dual phase approach. The first phase provides context and creates a base of knowledge that allows for more appropriate questions and probes as well as a connection with the participants. The second phase serves as the predominant form of data collection.

First, an observation of the centers was performed to gather data prior to the interviews with the study participants. This provided context and promoted understanding of responses from the women interviewed. By seeing the centers in advance, a commonality of understanding the structure and procedures of the on-site center was created. For example, knowing the form of the classroom, the drop-off and pick-up points, and location of the structure in relation to the workplace allowed for

\footnotetext{
${ }^{1}$ Mother's Magazine cites on-site childcare in naming its 100 best companies for women.
} 
commonality of reference. Also, this aided in the development of interview questions regarding societal determinants such as workplace structures. Furthermore, observing the centers in advance enhanced the connection with participants. The observations were arranged through the directors of the facilities with the full understanding of the research being conducted.

Additional contextual information was gathered by interviewing each of the centers' directors and at least two child-caretakers from each on-site center. ${ }^{2}$ These interviews were designed to gain further context, were semi-structured, and audiorecorded. Gaining insight into the philosophies and practices of the on-site centers allowed for a better analysis of the mothers' experiences. It also informed the interview questions for economic, societal, and functional determinants as well as provided a valuable perspective when probing further into participant responses.

The second and predominant form of data gathering was in the form of in-depth interviews. A total of 24 working mothers using on-site childcare and working at the location of the centers were the participants for the in-depth interviews. The mothers were drawn from four centers from four different industries, with a total of six interviews from each center. The total number of interviews is consistent with known qualitative research norms and has been found to be an effective number for drawing conclusions in phenomenological research. ${ }^{3}$ The objective of the interviews was to reach a saturation point with the information, and the interviews with the 24 working mothers using the on-

\footnotetext{
${ }^{2}$ Appendix A \& B - Preliminary Interview Questions ${ }^{3}$ Creswell (2007), “Qualitative Inquiry \& Research Design”, Recommends interviewing between 5 - 25 individuals; Page 61
} 
site programs proved to be sufficient in reaching this point. ${ }^{4}$ This was determined because the interviews yielded similar information across each of the sites.

These interviews were conducted in a semi-structured format to allow ample room for question probes, and flexibility for the participant to express herself. The location of the interviews was in a setting of the interviewee's choosing that she believed allowed her the opportunity to answer openly and freely. Allowing for privacy and a space that the participant found familiar and comfortable increased the likelihood of candid, forthcoming answers. Of the 24 participants, two chose to meet at sites outside of the workplace. The remaining 22 participants chose to meet at their place of work. These interviews took place in the participants' offices or workplace meeting areas such as conference rooms, alcoves and cafeterias. The timeframe for the interviews ranged between 45 and 60 minutes, with all of the interviews audio-recorded. The length of time was adequate to delve into specific aspects and thoughts that the women shared about their decisions and their experiences with the effects of on-site childcare. Interview questions were derived from the understanding formed in the literature review and developed to address how each of the decision making determinants is or is not influenced by using on-site childcare. The interview also included questions that asked the women to express their thoughts, feelings, and experiences with on-site childcare. ${ }^{5}$

\footnotetext{
${ }^{4}$ Interview results yield the same information. A term used in qualitative research. Creswell, (2007) ${ }^{5}$ Appendix C - Preliminary Interview Questions
} 


\section{Chapter 4 Process}

\section{Analysis Process}

Data from the interviews with the mothers was transcribed from the audiorecordings. Furthermore the data was managed through an inductive approach that summarized and synthesized the information. This was done by utilizing an open-coding, axial process. The codes were further categorized into themes. ${ }^{6}$ Horizonalization $^{7}$, the selection of significant statements, is used to demonstrate the themes. This allows for a textural description of the participants reported experiences. The analysis method took numerous passes to fully process the interviews, develop the codes, and identify the emerging themes; which culminated in the essential invariant structure, or essence, of the common experiences of the participants. ${ }^{8}$

Site observation descriptions and findings are gleaned from the field notes taken at the location. These are included to provide context and further textural description to the experiences of the participants, as well as informing the coding process and the creation of themes. Interviews with the on-site centers' directors and the caretakers are used in a similar manner to inform the context and develop a richer understanding of the participants' experiences. This has been done by transcribing the recorded interviews and utilizing a similar coding process to identify contextual themes. Ultimately, these too inform the themes recognized in the in-depth interviews with the mothers and advise resulting reports on the essential, invariant structure reported. The analysis of both the

\footnotetext{
${ }^{6}$ Theme is a phenomenological term that describes category of the experience.

${ }^{7}$ Moustakas \& Creswell (1994). "Qualitative Inquiry \& Research Design" page 61

${ }^{8}$ Appendix D - Analysis Example
} 
observation and the members of the on-site facility took place prior to the interviews with the mothers at the corresponding sites, so that the information would effectively inform the interviews. The second analysis took place after the mothers' interviews in order to place the information in context with the finding from the mothers. ${ }^{9}$

\section{Research Sites \& Participants Structure}

In order to maintain the focus on the research question, the participants meet the requirement of working at the selected organizations that have on-site childcare and use the service for at least one child. Mothers who use the facilities but do not work at the organizations, with access due to a spouse or partner, were not eligible participants. In the case of Portland State University, the mother was required to be an employee, not a student, of the institution.

It should be noted that a contrast group of women using outside childcare or mothers who have experienced both off-site and on-site childcare was considered prior to beginning research, but not presented in the research design. While this might have provided a valuable lens for information this approach did not focus on answering the primary question of the effects of on-site childcare. As seen in the literature review, much is known about mothers' decisions and factors surrounding childcare. What is unknown, are the effects of on-site childcare. Further, limiting the participants to those who have had a dual childcare experience would have eliminated women with early experiences using on-site childcare. These women hold valuable information that is fresh and contributes a critical piece to understanding the on-site childcare experience. Consciousness of this placed significant weight on the researcher to develop interview

\footnotetext{
${ }^{9}$ See Appendix E for a diagram of the analysis process.
} 
questions and hone probe-inquiries that get to the heart of on-site childcare. By noting this concern a richer understanding of the research design and methods can be understood.

The study used a snowball sample to locate participants. This sample method allowed for a warm introduction from referrals which helped to build trust. Gaining trust is a vital aspect to forming a relationship where mothers feel safe to express their thoughts, opinions and experiences in an atmosphere free of judgment. Without this crucial aspect the quality of the data for this study would be diminished. The snowball sample also provided growing access into a small community. By means of informational interviews, personal contacts, and access to several key informants, the initial contact vital for this approach was established.

However, there was one circumstance with Providence Health Systems where the snowball method was altered. Gathering referrals from other mothers came to a stall. This most likely occurred because of two reasons. First, the researcher did not have a key informant for the participant group and obtained the contact information of the first participant from a second party source which did not allow for broad relationship building. Secondly, Providence business units are often segmented, limiting the participant pools' connection with each other. This required the researcher to engage the help of the on-site childcare director. The director sent a broadcast email introducing the researcher to parents and allowed the researcher to introduce herself to participants in the lobby of the center. After the introductions, the remaining required number of participants were scheduled for interviews. This alteration remained in alignment with the intention of the snowball sample, by maintaining contact through a trusted source and 
a warm introduction. The results were positive interactions with the participants allowing for successful implementation of the interviews.

Sampling of directors was determined by the choice of organizations, and teachers/caretakers were selected by availability granted through the centers' directors.

The organizations with on-site childcare were carefully selected to give a broad sample of industries. The wide swath of organizations allows for a wide pool of participant experiences. Mentor Graphics Corporation is an Oregon high-tech software company. Providence Health Systems Oregon is a non-profit network of hospitals, health plans, physicians, clinics, home health services, and affiliated health services. Portland State University is an urban academic center. Nike Corporation is an international sportswear company. What the centers do have in common is that they offer on-site childcare that is open to all of their employees.

Each of the centers has received high quality ratings and similar curriculums. ${ }^{10}$ This is important because the focus needed to remain on the experience of the mothers using the centers and not depart into a discussion over differences in the childcare service quality. Portland State's Helen Gordon Center and Mentor Graphics Childcare Development Center (CDC) share the same curriculum called Reggio, while Providence's Wee Childcare Center relies on Montessori school curriculum that holds many of the same learning principles. Nike too has a progressive interactive learning system which is overseen by a pedagogical director.

\section{Individual Organizations}

\footnotetext{
${ }^{10}$ These reports have been verified by preliminary interviews with parents using the centers, site directors, reports from internal organizational surveys, and discussions with a union organizer for Providence.
} 
The noted commonalities of the organizations provide a platform for the following individual organization assessments. This is done to supply a richer understanding of the individual on-site centers and to provide further context for the primary results gathered through the interviews with the mothers using the centers. This information is obtained through an assessment of organizational facts, site observations and on-site staff interviews.

Nike

Nike is a $\$ 19.2$ billon $^{11}$ sportswear company headquartered in Beaverton, Oregon. It is one of the top 25 most diverse American companies. Nike cites that 40 percent of their American employees are minorities. The company also claims that 49 percent of their American employees are women.

They boast a 193 acre campus with two on-site childcare facilities. The first center is the Paterno Center and accommodates 200 children. The second childcare center, the Stringer Center, was built because of the overwhelming need and has opened to meet the needs of 300 children. ${ }^{12}$ Many employees were on the waitlist for years before the second center was built. The opening of the Stringer Center alleviated the extensive waitlist and allowed the company to achieve some of their efforts to being a family friendly organization. Nike's on-site childcare centers are by far the largest. This may be because nearly half of the employees are women and Nike wishes to retain and meet the needs of this talent pool.

The centers are LEED certified. A tour of the Stringer center revealed a state of the art center built for the needs of children. The windows, tables, chairs, and bathrooms

\footnotetext{
${ }^{11}$ Nike reported revenues for fiscal year ending May 31, 2009

${ }^{12}$ On-site centers populations stated in an interview with Nike Education Director, Laura Linda Negri-Pool.
} 
are all designed to fit the needs of the children at each development stage. The furniture is progressively scaled to meet the needs from infancy to preschool. Classrooms have an open feel with expansive windows looking into the classrooms from the hallways and large windows that provide views of the park-like business campus. Pictures of the children, notes about accomplishments, and current art projects serve as decorations on the walls. These touches indicate an environment that is welcoming and responsive to children. The campus has multiple athletic centers, ball-fields, a swimming center, as well as running trails, a man-made lake and spacious green areas. These are all open to use for the childcare center.

Nike possesses a very potent, intense organizational culture. Employees frequently referred to Nike as the only place they had ever wished to work. The draw seemed to be more towards the employer than the type of employment or the occupation. The campus buzzes with athletic, competitive energy and the prominence of culture is vividly displayed on murals, signs, and buildings. Each building is a tribute to an accomplished athletic figure, both in name and in displayed memorabilia. It is easy to see that this passionate culture would also carry into the on-site childcare centers where devoted employees, who find the culture a definite benefit, wish to socialize and care for their children. This shows in terms of how the on-site center is operated as well as the athletic focus of their curriculum and the cultural carry-over in terms of employee interactions aligning with Nike cultural norms and standards which were referred to as "Nike-talk" or using the center as a resource for product development of children's sportswear.

\section{Mentor Graphics}


Mentor Graphics is an $\$ 800$ million $^{13}$ software company headquartered in Wilsonville, Oregon. The Wilsonville site employs approximately 1,000. The company has a reputation of fostering employee-friendly policies with fair compensation practices and campus amenities that include a gym, cafeteria, and recreation center. The company is primarily an engineering organization and the preponderance of the employee set is male.

Mentor Graphic's Tom Bruggere Childcare Development Center is a 15,600 square-foot building designed to have a home-like feel. The on-site center serves 115 children, according to Childcare Director Gillian Brune. The entry way welcomes with overstuffed chairs and sofas. There is a distinct effort to provide a "cozy" setting with home-like furniture and children's art displayed on the walls. The classrooms are designed to fit the stage of the children in the room including child-size chairs, tables, toilets, sinks, and windows at both adult and child viewing levels. Alcoves are designed into the center for teachers working with small groups of children. The center sits on a spacious green campus next to a wooded area with trails and a pond that attracts wildlife which are open for use by the childcare center.

Mentor Graphics has an open, welcoming culture. This can be seen walking through the campus and watching employees interact playing pool or basketball during lunch in the recreation areas. Groups of runners can be seen at lunch time jogging on the trails and paths around the wooded campus. The recreation center, or commons, has signs for on-site massages and a place for haircuts. The CEO and president routinely have lunch in the cafeteria and chat with groups of employees over lunch. Awards for

${ }^{13} 2009$, 12 month report. www.mentor.com 
employee-friendly policies are prominently displayed in the commons area. These attitudes carry into the on-site center which, according to the on-site director, considers one of the center's roles to be to maintain a family friendly culture. More fathers are involved with the on-site center most likely due to the higher male population at the company. However, it can be seen that the size of the center is considerably smaller in ratio to Nike and this may also be a reflection of a higher male employee population. The employee population tends to be highly educated because of the nature of the work and industry. This appears valued and seems to carry over into the attitudes of the staff at the childcare center. Quality of service, education, and quality of life are cultural tones that carry over into the on-site center in regards to staff, curriculum, and appearance.

\section{Portland State University}

Portland State University is an urban academic center set in downtown Portland Oregon. It has a student population of 27,972 and employs 3,868. ${ }^{14}$ Portland State's Helen Gordon Childcare Center is open to both the student population and employees of Portland State. It serves as an academic laboratory resource, inviting participation by university faculty and students in the fields of early childhood education, child and family studies, psychology and related fields.

The childcare building is located on a street with a child play area that is fenced in from the street. The on-site center runs at full capacity with 170 children. ${ }^{15}$ The original brick building has an addition that was added with an effort to keeping the style and character of the original structure in mind. The building has a warm, old home feel decorated with pictures of the children and their artwork. The building has been retro-

\footnotetext{
${ }^{14}$ Fall Term 2009 numbers. www.pdx.edu

${ }^{15}$ Source Helen Gordon Director Ellie Justice.
} 
fitted to meet the needs and safety of children. It is a short walk to the main university campus located in a series of park blocks that boast large trees and benches. The university campus and buildings are open to the childcare center including art and science exhibits. According to campus sources the quality of the childcare center is notable as well as its substantial waiting lists, especially for Portland State employees. This is due to the policy that gives preference to students on the waitlists.

Diversity would only begin to describe the culture of the urban set Portland State University campus. The university seeks to meet the needs of a broad set of ages, ethnicities, and lifestyles in a campus that is not traditional in nature. Most of the student population commutes to the campus and holds their life activities away from the campus and the other students. This culture influences the childcare center in its reflection of valuing diversity and the acceptance of a range of life circumstances. The center reverberates flexibility with the needs of the parents' fluctuating schedules that often alter from term to term. Clearly education is a tone that is echoed in the on-site center and acting as a learning laboratory for students in education underscores the nature of the center. The cutting edge curriculum and methods are widely regarded and the childcare center routinely welcomes guests who aspire to create similar educational standards in their own childcare centers.

\section{Providence Health Systems}

Providence is a non-profit health care system that employs 16,409 people in Oregon. ${ }^{16}$ The Wee Care center is located on the lower-level of The Center for Medically

\footnotetext{
${ }^{16} 2009$ information on www.providence.org
} 
Fragile Children as a part of the hospital campus in Northeast Portland and primarily serves the employee population surrounding the hospital campus.

The Wee Care center serves at its full capacity of 75 children. ${ }^{17}$ The center was architecturally designed to be a childcare center with a covered, padded play area and age-appropriate facility, furniture and play-equipment. Entrance to the facility is directed through a state of the art security system with monitors. Parents use an electronic checking in-out system for their children. A receptionist is available for assistance at the entrance. The entry way has a fish-tank that provides educational entertainment for the children and serves as a conversation piece as the parents pick-up and drop-off their children. The classrooms have designated areas of entry for greeting and shoe removal which are structured in a way that leans towards classroom childcare instead of a home environment. All of the furniture and facilities used by the children are scaled for the children.

At its best the culture of Providence has a sense of care. However, as can be the case with constant requests of need caregiver fatigue can occur. The culture is highly segmented and hierarchical, which is indicative of the healthcare industry. Roles and responsibilities as well as titles are regarded and noted. Each business centers' employees seem to function for the needs of their own units, while following the standards and procedures of the larger organization. The childcare center seems to have taken the best of the culture with a genuine caring vibe that in many ways acts as a unifying and equalizing force for the parents using the centers.

\section{Ethical Considerations}

\footnotetext{
${ }^{17}$ Source Wee Center Director Colette Brown.
} 
Ethical concerns were addressed in advance of the study to lower the possibility of violations and to exercise the utmost respect and sensitivity. ${ }^{18}$ Retaining transparency in regards to the research process and goals sought to assure participants and to be clear about how their contributions and information would be used. A standard form approved by the Human Subjects Review Committee was used to assure each participant that she had the right to not answer questions or to remove herself at any time from the interview. Taking these actions to inform participants of their rights lowers the risk that they would feel forced into answering questions based on the authority of the interviewer. In addition to this, the confidentiality of the mothers was assured and data collection measures assured privacy.

In anticipation that the questions and probes may have been emotional for some of the participants as they relived their decisions or perhaps, in some cases, felt conflict over their choices in regards to childcare the researcher relied on training techniques received in communication, organizational psychology, and conflict resolution courses to create a non-judgmental environment. While there were no indications that the interviews caused such internal conflict, being prepared and sensitive to these possibilities was an important preparation step and precaution.

Similar procedures were taken with regards to the childcare centers. Observation of the sites was gained through the directors with full disclosure as to the intention, purpose, and methods of the research. Interviews with teachers/caretakers and childcare center directors remained transparent and the opportunity to opt-out was stated.

\section{Validity Measures}

\footnotetext{
${ }^{18}$ Appendix F - Human Subjects Review Application
} 
Numerous steps were taken in the research to assure validity of the study. Sampling participants using on-site childcare from four independent industries has increased the probability that the true essence ${ }^{19}$ of the childcare experience and the effects on the decision making process for this sample has been clearly understood. Some industries may draw on a particular type of employee or may have set cultural norms that influence the experience lens of the participant. By including a broad range of industries, the study increased the likelihood that industry specific responses are limited or perhaps eliminated in the development of themes through the process of analysis.

The use of multiple validating methods has increased the accuracy of the findings. Observation, industry member interviews, and the interviews with mothers using the onsite centers, provide vantages from many angles to paint a fuller representation of the onsite childcare picture for working mothers. However, while the benefits gained in contextualization through multiple sources is important to note, it is the experiences of the mothers using the on-site childcare that hold the most weight. Every attempt has been made in the information gathered during the observation and through on-site center's employees to inform and enhance contextualization, not to stifle or modify the mothers' responses.

All of the interviews have been audio-recorded and transcribed. This process increases accuracy of the participants' responses, as well as allows for transparency in the development of coding and determining themes. Quotes from the transcripts are also used within the findings report to provide context, examples, and to display contextual

\footnotetext{
${ }^{19}$ The term "true essence" is commonly used in qualitative research to describe the common experience of the interviewees. The distillation process of qualitative information produces the true essence of the research findings.
} 
sentiment expressed by the participants. Rich, thick description is also used to allow the readers of the research to determine the transferability of the findings. These methods are an essential part of the research and allow for increased accuracy in the interpretations of the findings.

Member feedback, where the participants respond to the findings, has also been used to assure accuracy of the reporting. While the method does not demand that every participant agree with every aspect of the findings, feedback from the participants adds another level of clarity and assures that concerns are addressed or revisited. Participants were emailed the findings in an attachment and asked for their responses for the editing process. In this research, the member feedback was minimal but unanimously positive. Three participants responded to the request for feedback. This may indicate a lack of controversy with the findings, as people are more likely to respond in disagreement than in agreement. Two of the participants could not be reached because their email addresses were no longer valid. This may signify that they are no longer working at the organization, because the email addresses were their work addresses. The responding participants expressed interest and shared more stories to underscore the findings. Negative case analysis methods were also utilized to ensure that all information was taken into consideration and that the results reflect and incorporate all of the findings. The method helps to limit researcher bias because findings that may initially be considered outliers must be qualified and taken into account.

Throughout the study, the researcher has held reflection periods and employed journaling practices to gain and remain conscious with regards to feelings, thoughts, and any biases that arose. While it is impossible for any researcher to completely remove the 
"self" from research, by including practices that promote consciousness the best efforts to remain open and report the findings accurately are achieved. 


\section{Chapter 5 Institutional Context Results}

\section{Institutional Themes}

The following institutional results set the context as well as corroboration, insuring validity for the primary results of the in-depth interviews with the mothers using the on-site centers. The following context provides results that are divided into themes based on the interviews with the teachers/caretakers and on-site center directors.

\section{Program Excellence}

As previously noted, factors in choosing the centers to be researched were equality in regards to quality of the centers and diversity of industry. All of the centers provided exceptional excellence in the quality of childcare provided. This is displayed through the following themes:

\section{Curriculum}

Curriculum development is an essential and core aspect at all of the centers. This begins with the directors and is reiterated by all of the teachers. Creating a learning environment that optimizes learning opportunities and enhances child development is a core concern at each of the centers. One teacher explained, "We have a system where we look at cognitive, social, emotional, physical, language and literacy." Another teacher explained, "We teach the children how to be professional learners." The top tier child education is possible at these centers because of funding support through the larger organization.

\section{Communication}


Communication is a common focus at the centers. Teachers begin and end the day with parent discussions. "The parents love the fact that they get that one on one consultation in the morning at drop-off," mentioned a teacher. The efforts at effective communication extend into the day through telephone conversations, emails, and through face to face interaction when the mothers come to the on-site centers during the day. A teacher explained, "We have email that goes out to the parents, which is pretty unique. I haven't seen that before. We also call a lot. If we have questions about their food or sleeping routines or how last night went we can just call them directly." Monthly newsletters are common among the four on-site centers. The centers also focus on providing additional training and education opportunities for the parents using the centers. The centers accomplish this through reading material, conferences, and providing after-work classes. All of these are optional, but the childcare centers report a positive response to the opportunities. Because the classes are a part of the larger organization, all employees are welcome to join. For example, if there is a three week class on discipline, parents not using the center may find an interest and attend. The efforts for extensive communication are enhanced because of organizational oneness. Email systems, internal computer systems, phone systems, and same-site location are options that create seamless communication situations. A teacher explained, "The parents ask questions about potty-training, and about if their children are developing OK. They worry and stuff. I try to be positive all of the time."

The centers make a concerted effort to ensure that the parents are informed as to the philosophies and structures of the centers by providing tours and information in advance of enrollment. The on-site centers are concerned that the organizational 
childcare centers do not become a default choice due to employment, but that it has been seen as only one of the options that parents may consider when choosing childcare. A director noted, "We require and encourage people to come tour the center in order to see if this would be the right fit for their child."

All of the centers support extended family and friend involvement. They consider it an aspect of parent support. This may include inviting grandparents, aunts, uncles, friends to the children's center sponsored art shows or inclusion in the emails and photos regarding the child that are also sent to the parents. Of course, all of the additional involvement is by parent approval and initiation. A teacher stated, "We strive for a sense of community; to not only bring moms and dads but grandparents come and spend time in the school."

\section{Partnering}

The teachers, caretakers, and directors concentrate their efforts towards creating partnering relationships with the parents. Many of them take their jobs personally and see it as a responsibility to develop deeper relationships because of the nature of the work. A teacher shared, "Relationships are important when you are caring for someone's child. There is nothing more precious to someone than their child. You don't need to be best friends with them, but you need to have a deeper relationship with them than you would with a bank customer. We are talking about human to human relationships."

The staff seeks to support breast-feeding for mothers. This is done through information, communication about the child's habits and hunger displays, as well as providing private space for nursing. A teacher noted, "We are an on-site program, that is one of the intentions of the program is to really support breast-feeding mothers and to 
support strong family relationships." Overall, the centers seek to promote parent involvement with their children at every development stage. "There is an open door policy where they are able to come and see their children in the day. They can take their children out of the center; we have an on-off policy. So if the parent wants to take an extended lunch they can come take their kids off for an hour and then come back." remarked a teacher. Another teacher said, "The parent involvement is much higher than any kind of off-site centers. The parent involvement is phenomenal. They are just more involved in their children's day and what they do."

The partnering relationship is enhanced because of low staff turn-over rates. The lower than average attrition rates for the childcare industry are most likely due to the support from the larger organizations that provides funding for above average wages and benefit packages, according to the findings from the interviews with the on-site centers' directors. Another reason may be that teachers prefer to work in top-tier educational environments that are supported by the organizations.

The centers further attempt to partner with the parents by offering both part-time and full-time options. A parent may choose what is best based on working schedules and/or by what would best fit the need of the child giving the child's current development, temperament and need. It should be noted that waiting lists, which are present at all of the centers, may inhibit the choice.

\section{Bonding}

The teacher stability allows for deeper bonds with the children. The bonding is also enhanced by the lower than mandated child to teacher ratios. Again, the support from the organization allows for these advantageous ratios. The centers also seek to pair 
the children with primary caregivers. This allows the child to have a point person who is consistent with them throughout the day, and in some cases moves with them through infancy to toddlerhood. In this way personalization is possible, even in a very large caretaking environment. A teacher explained, "Each child has a primary person. It is to help us feel that bond and relationship with the child, so that the child knows that we are there and can trust that their needs are going to be met."

Development of community is a priority for the childcare centers. With many of the families using the centers coming from isolated suburban environments, the on-site childcare centers seek to provide an instant community with the teachers, staff, and interaction with other parents. A teacher stated, "We fill the element of community that seems to be missing from modern society." The bonding through community is so pronounced that some of the staff will babysit or visit the children when they are not working at the on-site center. The teachers believe this is because the parents feel that they have an established relationship with the child and wish to continue it outside of the center for home childcare needs. One teacher pointed out, "A lot of us here at the center do childcare outside of the center because we build up such a good relationship with the families that they ask us to do the childcare outside the centers. It is really a community."

\section{Learning Centers}

The on-site centers consider themselves to be learning centers by continuously seeking to enhance and refine their approach. A teacher stated, "We are finding ourselves out there, beyond the edge. People are coming to us and looking at us as a model for the childcare community." The centers accomplish this by staying current with 
research and literature, continuing education for the teachers, soliciting feedback from the parents, and observing other on-site centers. After interviewing staff at the centers it is clear that all of the organizations observed in this research interact with each other. Several of the staff has worked at one of the other on-site centers discussed here. The staff considers the other on-site centers to be colleagues and they use the on-site status as an opportunity to learn about best practices through collaborative relationships. A director noted, "I really try to stay current and I interact with my counterparts at other centers." Another director noted that a core goal was to, "grow quality teachers; next generation teachers."

\section{Organizational Oneness}

The connection of the on-site centers to the organizations both physically as well as organizationally was the cause of the following themes that emerged from the interviews with the on-site center staff.

\section{Organization Strategy}

The on-site childcare centers are a part of the organizations and are included in the strategic organization planning. The centers are tracked for the impact on the organization both in terms of cost and benefits. Increased worker productivity and concentration, employee benefit, worker stress reduction, and increased retention were all advantages that the childcare centers were able to report. A director stated, "Once they have their kids in the center it does play a factor in whether or not to move." Another director noted, "My primary job is to the heart of our organization's mission which is to provide good work-life balance for families. The second one is to run a business model 
that meets the needs of the business." The childcare centers track these through parent surveys and statistical tracking methods. A director explained, "We survey people every year to have a more concrete way of gathering information."

\section{Center Funding}

All of the organizations provide financial support to their on-site centers and provide care for children from infancy through preschool. A director flatly stated, "We are an income spending facility." Another said, "Being aware of dollars and cents and how much it is costing the company is important." Employees using the centers pay a fee that is in alignment with the costs of mainstream commercial childcare centers in the Portland-metro area, according to director and participant interviews. However, the consensus is that a premium quality of care, services, staff, and curriculum are provided for the mainstream price. This would explain why organizational funding in addition to employee funding is required to maintain the centers at their current operating status. One director remarked, "This is an expensive program because we are running at a certain quality level."

However, the on-site centers are not funded and provided so well as to not have a waiting list. Every center had a waiting list, although the length varied by organization. Waiting lists can run into years depending on the desired age of admittance. Siblings are given priority status, so having one child in the on-site centers is advantageous to getting another in the center while the first is enrolled.

\section{Organizational Culture}

The broader culture of the organization has an impact on the childcare centers. This is due to the childcare staff being employed by the organization, the proximity to the 
broader organization, and the parents using the center also being from the organization. Nike held one of the most pronounced cultural influences, but all of the organizations used their mission statements and common practices to influence the tone of the childcare centers. One director noted, "We follow the same polices and procedures that are used system wide." Another director stated, "We are a part of a larger organization and if you are a parent here you are part of a larger work culture. It is the greatest thing to be part of the broader culture." "We are in sync with the rhythm of the organization," mentioned another director. The organization often uses the childcare centers to promote and manage an image and cultural norms. All of the organizations researched wish to be seen as family friendly and progressive. A teacher shared, "The whole culture is supportive of moms and their role of taking care of their kids." The organizations use this image for recruitment, employee retention, and to create a positive community image. A director observed, "Our program plays an important role, not only for the people who have children but also how the campus feels and how it looks to outsiders."

The childcare centers also influence the broader organization. The on-site childcare centers seek to remain visible on the organization's campus. This is done through the children moving through the campus as well as through organizational newsletters and announcements. A teacher commented, "They see us as we are going for walks or they see us outside of the buildings or whatnot. Just that is amazing!" The children often visit parents at their place of work, when appropriate, and utilize the facilities of the broader organization. The childcare centers also host art shows and display art created by the children throughout the organization. This allows for employees who are not using the childcare centers to have a connection and experience 
the influence of it. A teacher noted, "The audience is far reaching. Part of that is putting art in office spaces around campus so we could let the community know that this was going on here and if a parent saw his child's art in the lobby he could share that with his co-worker. It has its tentacles in many areas here." A director stated, "We work hard to maintain our visibility. We try to make sure the activities that the kids do are published in the office papers. We try to do a lot of community outreach." This exposure also solicits comments from employees about the center, both positive and negative. This is a situation the childcare center seeks to manage. A director observed, "The children are not tucked away out of site while the adults focus on their stuff. I feel like having an onsite center helps people recognize their lives beyond jobs."

\section{Segmented vs. Integrated Organizational Cultures}

Upon research within the organizations it became clear that there are two types of organizations, integrated and segmented. Mentor Graphics and Nike can be both categorized as integrated. While many organizations have departments and divisions, an integrated organization's departments seem to hold a greater symbiotic tie to each other and to the culture of the organization. The overarching goals of the organizations seem to tie the departments and the divisions together. Providence and Portland State University appear to behave as groups of individual organizations placed together. Each department and school seems to have a separate set of norms and goals, while still adhering to the larger organizational standards. There was little concern with a majority of the interviewees what was happening in other departments thus making it unnecessary for interaction of employees between units or department. This system may have emerged 
because a person developing her career within the biology department would have little concern or need to create relationships with individuals from the business school. Providence presented a similar situation. The units of operation were not dependent on success. The speech-therapy department had little connection or need to develop relationships with members in the elder-care services. Any connection between the departments would be for the need of the patients, but not necessary for career development of the employees. While there was overlap and networking in all organizations, the four organizations could be easily separated into the two groups. It is believed that the inherent behavior of the organizations was the reason why cultivating a snowball sample was more difficult at Portland State and especially difficult at Providence Health Systems.

The same analysis holds true for employment positions. Some roles demand more integration than other roles. For example a human resources director at Providence is more likely to find benefits and the need for integration throughout the organization whereas a lab technician may have less need for integration with other departments in order to progress successfully in her career. 


\section{Chapter 6 Primary Results}

\section{Participant Context}

To provide additional context it should be understood that the women interviewed tended to be advanced in their careers. The specific departments and roles varied significantly. Portland State held the least variability in roles with five participants in professorship roles and one participant in administration. However, all of the participants were from different departments and/or schools within the university. Mentor Graphics offered the most variability in roles which included a teacher, engineer, business analyst and participants with roles in marketing, human resources, and information technologies. Nike interviewees offered perspectives from backgrounds that included management from various divisions that interacted with domestic and foreign projects, as well as product development and graphic design. Providence, with its many departments and roles, provided participants with a range of backgrounds, including therapist practitioners, eldercare, medical-ware purchasing, and administrative recruitment. The vast variance in occupations within diverse industries, although none were entry level positions, provided increased assurance of a broad base of experiences from participants that serve to increase validity with the findings.

All but one interviewee was married or in a co-parenting partnership. Frequently the women's partners were also in well developed, if not more so, careers that provided well financially. The women described a considerable degree of support from their coparents as well as noting an emotionally supportive network of friends, family, and community. A significant majority of the women had delayed motherhood for career 
development, which often allowed them a greater degree of flexibility, establishment, and resources. As noted, many of them were in management careers that allowed for great autonomy and several expressed that years of 12 hour days had earned them the "right" to greater flexibility as well as had given them the chance to save vacation time. This type of planning allowed for extended maternity leaves and income during leave.

This context is important to consider in regards to the interviewees because such advantages may not be typical for many women seeking childcare. However, the types of organizations that currently have on-site care often use the care as an amenity to attract high-level, well developed talent. Thus the sampling pool of this research is most likely congruent with the users of other on-site childcare facilities. An understanding of the centers and the experiences with the women using the centers seeks to provide information to other organizations seeking to include on-site childcare as a part of familyfriendly policies as well as to inform urban planning policy as to possibilities to better support families.

\section{Theme Analysis}

The following themes resulted from an analysis of the data from the 24 interviews. They are categorized by effect, based on the literature derived broad categories of the determinants. The research found no need to create new archetype categories, but the themes do express new effects and impacts of on-site childcare that are not addressed in current literature.

\section{Economic Effect}

\section{A. Cost}


The cost of the on-site centers is comparable with the cost of commercial centers. The most frequently noted professional childcare used by the mothers prior to using onsite care is KinderCare. While the costs of the childcare centers are similar, mothers report that there is a difference in the quality of the care. "The company subsidizes the program somewhat so parents are getting even more than they were paying for." noted one mother. This is noted in terms of the design of the buildings, the play areas, the curriculum, the staff, as well as numerous additional benefits that mainstream centers do not supply. For example, Nike provides environmentally friendly diapers, Portland State supplies formula, and all on-site centers provide meals and snacks for the children. The on-site centers are also aware of meeting the individual needs of the child which may include a specific type of formula or adjustments to meals for food sensitivities and/or allergies. These additional amenities provided by the on-site centers act as additional savings for the families using the centers. One mother expressed her relief at the extra amenities of the on-site center by saying "They provide the formula with the cost of the daycare and they provide the food. We had our son in KinderCare before and we had to bring the bottles. At the time that was all he was eating, and luckily we got him in as he was beginning to eat food. Otherwise, I would have had to pack food and that would have drove me crazy trying to figure that out. It is hard enough with bottles and formula!"

While the cost of the on-site centers may pace well with mainstream options, they can still be expensive. The pricing models begin around $\$ 1,000$ for full-time infant care. A mother stated, "I needed to work full time to pay for childcare because it is so expensive." This expense can prove to outpace the salary of the individual. Some 
mothers noted that having additional children and placing them in the on-site centers would consume their entire wages. "I couldn't afford to have two children in the center at once so I waited until my son was out to have my daughter." said one mother. Another mother said, "As long as I am making enough to pay for the childcare and still bring something home then it is OK. If we were to have another one, we might lose that balance and it may not make sense anymore." Some mothers feel that it is an investment. One noted, "I am investing in my child because it is setting the foundation of who they are going to be as an adult. But gosh, monthly, after $401 \mathrm{~K}$ and childcare and everything I don't take home a lot of money." Due to the high costs, mothers make choices about remaining in the workplace based on the overall advantages of using childcare centers. On-site childcare at these organizations does not change this impact for mothers, although it does provide premium childcare at a mainstream pricing model.

\section{Societal Effect}

\section{A. Networking}

An effect of using on-site childcare is that it often expands internal networking especially within integrated companies. Mothers using the on-site center developed relationships with a diverse career set of people within their organization. Mothers noted that this allowed them to have connections and resources in other departments and to cultivate a broader vision of the organization and its goals. For example a mother working in the marketing department would find herself engaged with a parent at the center who was in the accounting department. Through continued interaction and inevitable discussions about work the two would have a greater understanding of the 
workings and goals of the other's department. Remarked a mother, "I also met other people in other departments that I would have never met otherwise and it did help. Because if you did bump into them for work, you already knew them and you already had a connection." The expanded view of the organization increased knowledge and allowed for better integration of the organizations goals, values, and cultural tone. "I know people in other departments that I would not have bonded with otherwise," stated one mother. The effect was less pronounced but noted at segmented organizations also. For example a Providence mother stated, "I may see them in the hospital and say "hello" to them but I am pretty isolated here in my office."

Another impact the interviewees reported were deeper, more personal relationships with their coworkers. The mothers believed that they developed closer ties with their coworkers using the center. A mother said, "I have worked with three or four parents now and you feel like you have more of a bond or a connection." The mothers also reported that their relationships with coworkers not using the center were also positively impacted. "Your co-workers actually have a chance to meet your kids and see your kids and that is kind of fun," stated one mother. Employees who had previously used the childcare centers would refer to it in conversations with the mothers currently using the centers. Several of the mothers found it to be a common bond. Senior management who had their children in the center 15-20 years ago would make reference and be a point of conversation with employees who were currently using the center. Additionally the mothers felt that the on-site center provided a platform for them to speak about their personal lives in a manner that was legitimized because the childcare center is 
a part of the organization regardless of whether the coworker had, at any time, used the on-site childcare centers.

When asked if the mothers had concerns about the personal involvement, exposure or if their involvement with the center had created awkward interactions none were found. The mothers unanimously had positive experiences. However, it may be prudent for organizations to be sensitive to this possibility if they have not already considered it.

\section{B. Organizational System Oneness}

The culture and management of the on-site childcare centers by the organizations has a marked impact on the tone and focus of the centers and affects the experiences of the mothers. Mothers noted a sense of comfort in knowing that the teachers and caretakers at the on-site childcare center are employees of the organizations because they had confidence that the on-site workers had been through the same vetting process that they had and felt that their company would seek to hire the best employees. The mothers also felt a sense of ease in that the culture of the organization was brought into the center. For example, mothers using the Nike center endorsed the focus and attention of the curriculum on athletics and sports centered activities. One mother stated, "The coordinator brings a "Nike feeling" into it. It is a creative culture and that is a great benefit to me." The mothers at all of the institutions found that the same interaction styles, norms, and terms that were used in their daily jobs transferred to the on-site centers allowing for better communication as well as common values. While all of the mothers interviewed found these organizational culture alignments to be beneficial, it may be difficult for a parent who did not associate well with the organizational culture. 
However, none of the mothers interviewed had this experience. One mother said, "It has been very positive because I know that his teachers and the directors are aligned with the same mission as my work here. So when we do our work, they have the same training and same development that we have here. I found that to be very helpful. When you go into the hallways you see the posters and it is the same values and same mission statement. It just seems like we are aligned. I know that [this organization] hires and attracts quality employees so it helps me in knowing that my son has the best quality of care that he can have."

Interviewed mothers believed that there is greater transparency and observation of their children at on-site centers. They believed that the organization maintained a firm control on the quality of the childcare centers as well as noting that other parents would be in and out of the center regularly and would note how the other children were doing. Mothers expressed that if their colleague saw their child at the center he/she would send an email to tell them that the child was doing well or if he/she was upset. This added another layer of communication and comfort for the mothers that they believed could occur because of the connection with the organization. "A big plus is that I work with a lot of parents who go to the center so I know them and that gives me an added sense of security because when I go over and see my other colleagues' kids there I look out for them and I know they do that for my child too." remarked a mother. Another said, "There are so many eyes on the center and you talk with others in the hallways and ask about the teachers and the policies. So you feel like there is a safety net, instead of only seeing a group of people at drop-off and pick-up. This way it is much more of a community." 
A greater sense of community was noted because the childcare center was integrated into the organizations. The mothers felt this because the workers at the childcare center, their fellow parents using the center, and the organization as a whole were all part of the same group that had common goals. A mother stated, "You know your peers trust them and people you respect trust them. It just gives you a better feeling in general." This situation was also noted because the centers are in sync with the calendar system of the organization, keeping the same holidays as the larger organization. Mothers who had used off-site centers noted that was an inconvenience in using the offsite centers because they kept a different calendar and vacation schedule that created incompatibilities. One mother observed, "I think they [the company] are more flexible and understanding about my leave because they understand how the childcare center works."

Due to the systems being united, the mothers felt that expressing their needs and concerns was more likely to be heard. One mother noted that because the teachers are fellow employees, they take your complaints or concerns as seriously as typical coworkers. The mothers also believed that their concerns had the backing of the larger organization and finding solutions was in the best interest of the entire group.

The influence of the organization's connection to the on-site center was also noted as the mothers reported that their experiences with calls from the on-site childcare center are taken more seriously by their managers because it is an organization employee calling. The mothers believed that a mutual respect amongst employees allowed them to respond more quickly to the on-site centers calls and requests because it was legitimized as a request from a segment of the organization. 
The older children using the center seem to be aware of the connection of the childcare center to the larger organization, according the mothers. The children are invited into the office and working spaces of the parents, when appropriate, and often know where the parent's office is located. An interviewed mother observed, "I think if they weren't on-site they wouldn't understand that mom has her office and work environment." The mothers use this as a bonding point by including their children in the organization. For example some mothers would say, "We go to work at Providence." Another example would be, "You're a Nike kid." This association with the organization most likely occurred because of the strong influence of culture on the on-site childcare systems. A mother shared, "One thing we were able to do was have her whole class come to my building and see my office and come in the conference room like that and see what a meeting is all about, so that she has a better understanding of what I do." The children were also reported as knowing the organizational logos and in the case of Nike were already expressing brand loyalty to "their" company. A Providence mother noted that, "We all have the same badges and she always plays with it and noticing other people who have it." A Nike mother stated, "I think he likes being a part of Nike. There are a lot of times, even in the daycare, where they bring the sports into the daycare and he definitely recognizes the Nike swoosh and he has already commented that his playground is better than the one that he is going to for kindergarten." Mothers at Portland State University found special value in the access their children had to academic exhibits from the art, and biology departments. One Portland State mother seemed particularly delighted by her son's joy in paleontology. 
It is believed by the interviewees that there is a symbiotic influence between the organization and the on-site center. They believed that most likely the organizations created the on-site centers in an effort to be seen as employee-friendly and to create a draw of high quality employees, but that the on-site centers influenced the evolution of family friendly policies. Seeing the children on campus and having input from the users and workers of the on-site centers perpetuated and aided in the evolution of family friendly policies. "I think having the children here and so visible renews the company's idea of what that means and challenges it to be up to date." stated one mother. However, mothers also noted that their experience with the organization in terms of being a familyfriendly environment was most heavily influenced by their direct managers and departments. One mother noted, "My department is good about it because my supervisor is a single mom and my department is good about family issues but I don't know about the company as a whole." Some mothers in the same organization, but different departments had significantly different experiences with family-friendly policies and attitudes within the organization. The consensus was that the organization needed to strongly promote a family friendly environment in order to influence the style of individual managers. One mother explained, "I think the family friendly nature of the company depends on the manager." Another mother observed, "I know people whose kids were sick and their manager just doesn't really understand or thinks they are trying to take time off. It definitely varies throughout the organization." These findings are in alignment with current literature on the implementation of family-friendly policies in organizations, as noted in Chapter One. 
While evidence of organizational influence was expressed by the interviewed mothers in all organizations, it should also be noted that the degree of organizational influence on the on-site centers was more pronounced with the integrated organizations and generally a lesser influence was noticed in segmented organizations, especially Portland State University. This may be because the other organizations sought to create a more specific culture in alignment with their business models.

\section{Family/Community Perception}

On-site childcare did have an impact on family and community perceptions in cases of mothers who were a part of traditional role communities or those who worked with individuals from traditional role communities. Mothers found that when people from their traditional communities initially found that their children were in childcare they felt a sense of disapproval; however upon learning that the children are on-site their attitudes shifted. "We're fairly religious and in our religion there is some pressure for the women to stay home and take responsibility for the children and the care-giving. This is changing with modern times, but when they hear that they are on-site it is like "Oh they are on-site! You get to visit them during the day." I think that people are more accepting of that than if we're dropping them off and not seeing them for eight hours." noted a mother. On-site care was seen as an opportunity to parent and connect with children in ways that those of a traditional mind-set found satisfactory. This was the case even if the mother did not regularly meet with her child during the day. Simply the idea of access was enough to soothe disapproval from traditional communities. One mother, who worked with elderly populations, would initially receive thinly veiled disapproval through raised eyebrows and expressions of concern for her when they learned her 
children were in childcare. Yet, upon hearing that the children were at an on-site center the elderly person would reverse course with looks of approval, and kind words about being a good mother. This mother believed that sharing this information eased her interactions and allowed for greater success because of the approval she received from the elderly population she often engaged.

Mothers also expressed that their friends, families, and communities envied their access to on-site childcare and frequently called them "lucky." One mother said, "A lot of my friends are envious, including some friends [at the company] who are still on the waiting list." It was seen as a status symbol amongst many groups. "My friends are jealous. It makes my job look pretty good." said one mother. Mothers noted that their friends would often use their lack of access to on-site childcare as the rationale for not working or delaying their careers. One mother commented that she did not want her friends to think she was "gloating" and did her best to refrain from mentioning the on-site center too often.

It should be noted that the majority of the population interviewed did not have concerns or interactions with individuals who hold the belief that women with children should remain home to care for them. This may have been based on the sampling pool which was largely educated, career-oriented mothers who either came from supportive progressive communities or chose to surround themselves with such.

\section{Mothering Style}

On-site centers did impact mothering styles of the interviewees. The mothers stated that they often looked to the centers to provide parenting advice and support in their parenting choices. The mothers often believed strongly in the philosophy of 
teaching and raising children in the matter that the on-site centers promoted. A mother noted, "I feel more educated and more involved. I see what they are doing in their classroom and I extend that." The on-site centers' employees were often referred to as "the experts", especially by first time mothers. Noted by one mother, "I have definitely learned from the center not only from the reading material they give you but also from being in the environment and observing how they handle situations and to have the resource to ask questions and have consistency in how the kids are at home and how that is being reinforced." The mothers continued to refer to staff at the childcare centers as partners. While this relationship may be developed at off-site centers, the increased interaction, access and sense of community the on-site centers offered enhanced this partnering experience. One mother said, "I've learned a lot. In fact the first thing I learned was to crib-train him. They helped him nap in a crib during the day and then they gave me tips. That is one thing that is great is that they reinforce what they are doing in the classroom and what I can do at home."

The mothering style was also influenced by the access available to the mothers during the day. Mothers stated that the on-site centers allowed them to be the "kind of mother they wished to be." One mother explained, "I love the convenience that you have the ability to pop in unannounced. Otherwise you'll have to trust that he'll be OK. When he was at KinderCare I wasn't able to check in on him as often as I wanted to." Another mother said, "I think it is unfair to the bond of the mother and child to have that much distance between. I mean if you count up the number of times that I found my kids on the playground for a wave or a hello, and that connection made such a difference. I knew that she was OK; she is right here." This sentiment held with all organizations, but 
especially the integrated ones and where mothers did not have rigid work schedules. Several mothers said that their children had their first solid food at the on-site centers because they felt best sharing the experience under the guidance of the on-site staff. The mothers would leave work for a period and go to the center for milestone moments. The option to be involved during the day or to make choices in regards to breast-feeding was particularly influenced by the on-site location of the childcare centers. Not only did the mothers feel that the increased access to their child through the day allowed them to meet the physical needs, it allowed them to meet the emotional needs of the child. This was enhanced because of communication with the teachers and caretakers throughout the day that allowed them to be alerted to the moods and behaviors of the child.

Another aspect that impacted mothering style was the cohesive strategies to incorporate home strategies and preferences with those at the childcare centers. The teachers and mothers would regularly converse in order to ask about people and events that happened over the weekend, about discipline strategies, toilet training, or any other important topic to the child's welfare. These were underscored by the mother being able to access or even intervene on a situation based on a call from the on-site center.

\section{Functional Effect}

\section{A. Waiting Lists}

Waiting lists are consistent problems at all of the centers. Some centers such as the site at Portland State and Providence have especially long waiting lists. One mother noted, "Most employees don't get in there, so it isn't a reason for people to work here."

Prior to opening a second center Nike had waiting lists that exceeded two years and 
mothers using Portland State's center expressed similar waiting periods. This seemed to be especially problematic when mothers returned to work and wished to breast feed. The ease of access to their child for nursing was a primary concern for the mothers and several felt disillusioned because while pregnant they believed that the on-site center would allow for ease of nursing upon returning to work.

Expectant mothers are placed in a difficult position in the cases of long waiting lists. At all of the centers the women must be pregnant in order to get on the waiting list. Some women revealed discomfort in putting their names on the list upon learning of their pregnancies due to fear of disclosing the pregnancy earlier than desired. A mother pointed out, "I was four months pregnant when I got her name in, just when I was sure it wasn't going to be a miscarriage and even then that is very presumptuous in pregnancies." However, the women who placed their names on the waiting lists as soon as their pregnancies were confirmed felt that this strategy was the only way to ensure the need for the childcare of their choice would be met. "I actually had the application filled out before we were going to try," said a mother who got into the center after an extended maternity leave. In an extraordinary case, one mother put her name on the waiting list upon learning of her pregnancy but the pregnancy ended in a miscarriage. She left her name on the list and became pregnant again. It was because of the extended time on the list that she was able to get her child into the infancy care. Had the first pregnancy matured, she would not have had her child in care until the child was over a year old! In some cases waiting lists are so long that access to an on-site center is not a consideration for working at the organization because there is little chance of ever getting in the on-site center. On-site centers do not appear to influence when a mother returns to 
work, but is a factor in whether the mother returns to work. ${ }^{20}$ Many expressed that they would not have returned to work if an on-site center was not available to them. "My oldest couldn't get a spot right away so I ended up staying out of work for four months. My second got in right away, so I came back a little bit earlier." noted one mother. Therefore, it is reasonable to assume that extensive waitlists with on-site centers may be a contributing factor to employee attrition. Thus organizations that provide centers as an employee-friendly amenity that attracts superior talent should seek to monitor waitlists.

Some mothers have access to family care and prefer to use this service during early infancy. This option and choice works well for some of the mothers who wish to refrain from using a commercial center in the early months. For these women the waiting list is less of a burden given that their preference is to wait until the child is older. Being aware of the long wait times these employees put in the names of their children in infancy and have been pleased with admission to the centers after a year or two has passed. While this strategy works well for women who would not have used the center in the child's infancy it still leaves the mother to speculate when care will be available and how to manage family members' expectations as to how long the length of their service will be necessary.

\section{B. Quality of the Center}

The mothers' impressions were that the cost of the on-site center was comparable to mainstream commercial centers, but that the quality of the on-site centers was considerably higher. "I went to look at alternate opportunities and I didn't like what I saw." stated a mother. The quality of the centers was of utmost importance to the

\footnotetext{
${ }^{20}$ For additional explanation refer the effect of on-site center on employee loyalty.
} 
mothers interviewed. Most cited that this was a more important factor than the location of the center. One mother gushed, "They have a room for sanitizing toys, just like you would see in a restaurant. It is a room, just for cleaning toys! That kind of thing is important to me." Many mothers felt that the physical details of the center were indicative of the quality of care, concern and attention to detail that centers exercised.

Excellence practices of the centers that set the on-site centers apart from mainstream commercial centers included grandparent and extended family involvement and the welcoming open atmosphere that encourage participation with the children in the center. Participation includes sending email and photos of the children involved in their activities during the day to the parents and others the parents wished to include such as grandparents, aunts, uncles, and friends. One mother noted, "My friends and family think it is amazing because they are able to come and participate in activities like birthday celebrations and potty parties." The high level of inclusion allowed the parents to discuss the days' happenings with their children and allow the children to talk about the pictures and their experiences after the work day. Mothers consider the on-site centers to be of such high quality that there is concern over transitioning to public-kindergarten. One mother said, "When he is off-site I don't know what is going to happen. I don't know if it will change how I feel about being a working mom."

The access to services and the low attrition rates of teachers also enhanced the feeling of a high quality childcare experience. Mothers often complained about the high turn-over rates of teachers at other childcare centers that they had used. Another commonly cited benefit was that there are low teacher to child ratios at the on-site centers. "They are all certified childhood educators, so it is a learning environment. It 
isn't a daycare where they are sitting on the floor and not learning. The kids are literally learning from the minute they go until the minute they leave." stated a mother. "They have started him on swimming and they have six weeks of yoga, soccer, and t-ball.” noted another.

Communication between the teachers and parents seems to also confirm the high quality of childcare with the mothers. The teachers at all of the centers make a marked effort to talk with the parents to understand their parenting motivations and align home and center practices. This generates a feeling of being heard and valued by the teachers, thus enhancing their experience with the on-site centers. All of the architecture and facility design, noted previously, are also valued by the mothers.

While it is possible for these experiences to occur at off-site centers the subsidized nature of the facilities allows all of highest quality experience for the mainstream price. Many mothers would not be able to afford the high-level childcare centers as well as access to these centers can be prohibitive and limited. An additional benefit of on-site centers that may allow them to offer excellence in childcare is that the teachers and care-takers are employees of the organization. This comes with higher than average industry wages, benefit packages and attracts top childcare talent that often chooses to stay with the organization because of the benefits not often found in other childcare positions. While none of these attributes are directly related to the center being on-site, there is a direct correlation to the excellence of the centers and the support of the larger organization.

\section{Work Time}


On-site childcare had varying influences on work time. Some of the mothers noted that because they did not have extended drive times they could stay at work later. If they had to drive across town to pick-up their child they would have to leave work earlier to meet the pick-up deadline. For some mothers the hours of operation conflicted with the required work hours. Very early or late meetings were difficult because the onsite center was not operational during all of the required organizational work hours. This concern prompted some mothers to note that they worked less because of the centers hours. While the mothers noted that the problem would be the same with an off-site center, some of the mothers believed that because the childcare was connected to the organization their work hour needs should be accommodated or adjustments to work demands should be made. While the conflict in scheduling was expressed by some mothers at all of the researched on-site centers, it seemed particularly problematic for professors at Portland State who felt disadvantaged because their work contracts for the terms would begin before the arrival of students whose calendar dictated the on-site center's days of operation. Other mothers believed that the restrictions caused by the onsite center's operation hours increased their work-life balance and saw this as a reminder to prioritize family time. A mother remarked, "Before I had kids I worked from 9:00am to $8: 00 \mathrm{pm}$, if I needed to work late back then I could. Now the center is definitely open only during set hours so I have to adjust my schedule accordingly, but I think in a good way. I think it has helped me put things in perspective more and I strive to more of a balanced lifestyle." One mother took note of the situation saying, "I don't get to take more breaks during the day than anyone else, it is just that I am using my breaks in a different way. I choose to go to the childcare center while some of my co-workers may 
choose to go to the gym and workout instead." "It shouldn't be just work, work, work, but it shouldn't be just kids, kids, kids either." noted another mother.

The on-site centers may improve the quality of the work. Many mothers pointed out that because they have increased peace of mind and lower stress rates they feel that their work is done with greater efficiency and with less distraction. One mother explained, "I have to do my work either way, but this gives me a lot of peace of mind. I think that if you have peace of mind you can put $100 \%$ into whatever you are doing." Another said, "The childcare center makes you more productive."

None of the on-site centers offered evening hours for care. While employees working at organizations that run on typical business hours may not find a need for this service, health-care workers are routinely asked to work night shifts and professors are often required to teach evening courses. With the current situation on-site childcare would not be available for them. A mother observed, "I have a set schedule, but if I had to work the night shift then I would have to find childcare at night and that might be tricky."

\section{Commuting Time}

Commute times were positively influenced by on-site centers. Mothers appreciated that there was not additional commute or drive time required to get to the childcare centers. "It does make it easier that we are going to the same place. It cuts down on any extra travel time." noted a mother. The ease in dropping off the child and in most cases simply walking a short distance to the work building was considered a highly favored benefit. An interviewee noted, "It is really nice because I drop them off and then come behind the building and go to work. It works out well." Another commented, "The 
biggest benefit is the close drop offs. My friends have to drive a half-hour each way to drop off their children. That is something I never think of. I am so grateful for that. I can’t imagine adding another half-hour to my work day before and after."

Mothers also noted that they found the drive time with their child to be a special time of connection and bonding. It was noted that the drive time provided an uninterrupted time with the child to talk and relate. The mothers noted that while at home the children would be distracted by their toys or that the parents would be working on other home projects, but that while in the car deeper development of conversation occurred. Several mothers who had initially had their child at care centers close to their homes before transferring to the on-site centers noted that this time in the car together was an unexpected benefit and that they had actually begun to value their commute time. A mother explained, "You get time with your kids in the car on the way home. You have that conversation and it is actually a much richer conversation than the one you have when you are home. You are kind of stuck in the car, so you might as well talk." Another mother stated, "We are together more as a family."

Childcare centers close to home, while not adding drive time did present other concerns with timely access to the child. A mother stated, " Things that make me nervous about having childcare close to our home is that if my child gets sick or hurt she is a half-hour drive from me."

\section{E. Nursing/Lactation}

On-site childcare significantly impacts mothers who choose to breastfeed. Access to children during the day allows for extending nursing periods. For some mothers this was cited as the most significant and critical benefit to on-site childcare. "I am a fan of 
on-site childcare especially when they are infants and you don't have to stop nursing. You can nurse and spend bonding time with them several times during the day all the way up to pre-school." one mother stated enthusiastically. The childcare centers were supportive of the nursing. One mother explained, "They would call me if they would see her sucking her thumb or hand and see the cues so that I could get over there before she started crying. I always felt connected.” Mothers often complained that pumping, bottling, and clean-up took longer than a walk over to the on-site center and also allowed them to personally connect. One mother stated, "Pumping is just no fun!" I want to see my child's face and have that interaction and bonding with him that comes through breastfeeding." Another said, "Because I didn't get into the center right away we were at the YMCA and I had to pump his bottles. I don't like pumping. That was a big drawback for me." Mothers who used the on-site centers while they were breastfeeding found the experience very positive and several believed that they would not have maintained the breastfeeding if they were left with pumping as their only option during the day. Underscoring this, mothers who had rigid work schedules and were unable to leave work to breastfeed weaned their children upon returning to work. Even with onsite childcare, the type of job and support received from management affected the choice to breastfeed. A mother pointed out, "I went over everyday at noon and nursed him. I just scheduled it in the day."

Breastfeeding typically takes place during infancy, and mothers who were not admitted to the on-site centers due to the waitlist list expressed frustration over this situation. Given that breastfeeding is highly impacted by access to on-site childcare, 
extensive waiting lists can remove this significant benefit for nursing mothers returning to work.

\section{Psychological Effect}

\section{A. Guilt}

An unexpected finding directly associated with the childcare facility being on-site was that some mothers had an experience of guilt. The close access to the child can create a sense of obligation to visit the child through the day, even when it is not feasible with the work schedule or the child's care schedule. It was not a universal experience, but several mothers felt divided as to how their time should be best used. One mother stated, "I do feel a little guilt that there are other parents going over every single day. I think should I be going more often?" The sense of internal conflict seemed to be centered on the ease of access to the child prompting several women to lament that if the child was at an off-site location, it would be impossible to visit and not a consideration thus easing the conscience. This lack of a visiting option seemed to allow the mother to feel that it was beyond her control to visit and therefore lessen the belief that she was responsible to visit her child during the day. Being on-site added conflict because of the supposed ease of access, and contributed to the mothers' feelings of guilt. Upon admission of feelings of guilt, the mothers would be able to logically explain why the internal controversy was unnecessary by noting that visiting during the day could prolong the workday, interrupt the child's education schedule and that simply the nature of the work demanded attention during the day which was the primary reason childcare was being used in the first place. A mother noted, "It is too hard for me to take my mom hat 
off and put it back on and go back to work. For me it works better to drop off and pick up and not spend too much time in the middle of the day. There is an issue of transition." While these logical explanations eased blame in external reasoning the internal conflict appeared to remain for some women.

Some women felt that they had initially felt this internal conflict and guilt but that over time they were able to ease this feeling by finding a balance with their work schedules and visiting hours. For example, some women would attend events that the onsite center was hosting like a hike, diversity celebration, or ice-cream party. By attending these events some mothers felt that they had found a balance in utilizing the access to their child during the day and their need to be at work.

Another solution to the conflict, some mothers confided, was a supportive childcare staff. Some mothers mentioned that they initially felt conflict but were reassured by the staff that their attendance during the day was welcome but not necessary and that in some cases could interrupt the child's schedule. Staff confronting the problem with reassurance appeared to be an effective solution for the mothers because the advice received was through a professional involved with their child and whom they considered held the best of the child in the forefront of their attention.

The age of the child seemed to be a factor in whether or not the mother held any guilty feelings about visiting their child during the day. New mothers with younger children seemed to be the most conflicted where mothers who had more than one child at the center or who had time to adjust to the childcare routines seemed to have less associations with guilt or expressed that they had overcome feelings of guilt.

\section{B. Stress Management}


On-site centers offer peace of mind to mothers. First time mothers and mothers new to childcare found the location of the center particularly comforting. This phrase "peace of mind" was universal with the mothers interviewed. Whether or not the mother visited the child during the day, the idea of quick access to meet the needs of the child especially in an emergency was cited repeatedly. "I can be there in 5 minutes. If something happens, if he gets sick. I can be there instantly. One time he fell off the play structure and go the wind knocked out of him. I was able to check on him and then go back to work," stated one mother. Some mothers had used off-site centers close to their homes prior to using the on-site facility and while the location seemed to work well in regards to pick-up and drop-off, the gap in time to get to the child in an emergency or illness was a point of stress that the on-site centers unanimously addressed. It was often said that this "peace of mind" allowed for higher quality of work because the mother felt that she could concentrate more effectively knowing that if a problem were to arise there would only be a short gap of time in being in contact with her child.

The mothers' positive impressions and the positive feeling of their children about the centers also lowered stress. "It makes it easier to do my job. It gives me peace of mind." said an interviewee. It was repeatedly noted how much the children enjoyed being at the centers, especially as the children aged. Frequently parents would comment on how much their children loved going to the center. The children seemed to express their joy with their teachers, learning and especially making friends. While this could have happened at any childcare center, it may have been enhanced as a by-product of being an on-site center. The quality of the centers being supplemented by the 
organizations may have increased the experience. ${ }^{21}$ Whether or not this is the case, it can certainly be stated that the children's appreciation of the center lowered the stress of the mothers.

Many mothers felt that having the centers on-site allowed them to better bring work-life balance into their jobs. Visiting the childcare center during the day or even having the reminder of their children on campus created a situation that set priorities. This alignment of priorities decreased stress for the mothers because they felt that their attention was directed to the bigger picture of life values and away from a narrow view of their jobs being their entire life identity. Several of the mothers felt that simply the presence of the centers on campus and seeing children on the campus provided a reminder of life values to the entire organization regardless of having children at the center.

\section{Employee Loyalty}

On-site childcare is typically not an influence to work for an organization, but it has a direct influence on mothers remaining at the organization. Most of the mothers interviewed choose to work for the organization before they made a choice to have children. Most of the interviewee had developed careers at the organizations with little more than a cursory knowledge of the childcare option. A mother noted, "When I started working here I was 22 and single. I knew about the center, but I just thought - oh that's nice." Women who were mothers prior to their employment with the examined organization were heavily influenced by the access to on-site childcare. One interview revealed a mother returning to the workforce who specifically sought to work for an

\footnotetext{
${ }^{21}$ Correlations also discussed in "Quality of Center" theme.
} 
organization that had on-site childcare and rejected job opportunities without on-site care. She stated, "They call it handcuffs at the center because once you get your kid in there it is so easy and convenient you can't leave." The exception to mothers feeling influenced to take jobs with organizations with on-site centers were those working at Portland State University. In these cases the interviewees were professors who believed that due to the limited number of professorships available in the workplace access to on-site childcare would not be nor was a primary influence to accepting their position within the university. It was noted that the on-site centers were a positive benefit, but not a decision making factor.

It can then be concluded that on-site childcare may be a draw for women who already have children but is not a significant draw for women who are not currently considering motherhood or for women with seeking employment with highly limited opportunities. However, whatever the initial draw to the organization, mothers unanimously cited on-site childcare was a motivator to remain at the organization. In several interviews the mothers stated that they would not have returned to the organization had it not been for their access to on-site childcare. One mother stated, "I wasn't going to go back to work after my second child because of the cost of daycare, but my first loved it so much that I am back at work just to have the daycare. My daughter loves it that much! Every night before we go to bed she asks if she'll get to go to school tomorrow. That makes me feel good." She also stated that while the on-site center didn't initially draw her to employment at the organization, "The only way I was going back to work was if my kids got in the on-site center." Another reflected, "What caused me not 
to be recruited away was the on-site center because this other organization didn't have on-site childcare."

On-site childcare has a positive impact on employee loyalty and work motivation. A mother stated, "It definitely makes me want to continue to work hard and do what I can to be able to stay at the company and reap that benefit." Mothers stated that they felt heartened to do well in their jobs in order to maintain their access to on-site childcare through being seen as a valuable employee to the organization. According to one mother, "It supports my desire to work." "I don't think I would have gotten tenure if not for onsite childcare." remarked a mother. Another mother said, "For the most part it has led to a higher job performance and higher job satisfaction because my kids are here. If I am having a hard day I can go see them and I don't feel like I am missing a lot of work."

Children's establishment in the center also increased employee loyalty. Mothers did not wish to move their children once established in a center because they believed it would cause a disruption for their child. This even seemed to be a consideration for mothers who initially established their children in an off-site center. A mother pointed out, "I had a hard time deciding if I wanted to move him, but I decided he was young enough that the transition wouldn't be too hard." They noted that they gave it great consideration before moving to the on-site center. The need to enforce consistency and stability at a center was a serious consideration and decisions to move even to an on-site center or to another company with an on-site center were heavily scrutinized. This information may encourage organizations to maintain shorter waitlists because it would allow employees wishing to use the center to establish their children in the center upon return to work, thus solidifying employee loyalty to the organization. 
On-site childcare centers have an influence on employee satisfaction with the organization as well. Utilizing the centers has a halo effect on the organization where women tend to see the organization as more caring about their personal needs and employee friendly. One mother remarked, "It is very positive. Not only because it makes things easier for us but I respect my employer a lot more because of it." The women are conscious of their own shift in attitudes about the organization from their time prior to using the center and after using the center. This increased level of satisfaction also influences employee loyalty positively. A mother said, "I think it is a tremendous bonus to have it. It is my top three attributes for the workplace. Maybe it is number one right now. For someone like me who needs that childcare, I am going to be here for a long time. Even if it were a strong economy I would not look elsewhere right now. I think it is a huge retention factor." 


\section{Chapter 7 Conclusions}

\section{Research Summary}

Access to satisfactory childcare is of primary importance for women's ability to retain employment as well as overall economic stability. Finding solutions to women's needs in regards to childcare is vital for a successful society as measured against the principles of feminist urban planning and feminist organizational theories.

The goal of this research is to understand the effect of on-site childcare on the working women using the service. Twenty-four mothers, employed by four organizations in different industries that offered on-site childcare, were interviewed. The number of interviewees allowed the research to liberally meet the saturation point, ensuring confidence in the findings. The literature review provided a foundation of knowledge regarding the factors and considerations that function as determinates for women concerning childcare decisions. The current literature yielded information that was sorted into the broad categories of economic, societal, functional, and psychological factors. These categories provided the foundation for development of the interview questions and allowed the results of the interviews to be categorized, as themes, under the corresponding area of impact. The findings, while new, were still under these categories.

The following list summarizes the categories and the subtopics that were most prominent in the participant interviews.

- Economic Effect

○ Cost

- Societal Effect

○ Networking

○ Organizational System Oneness 
- Family/Community Perception

○ Mothering Style

- Functional Effect

- Waiting List

- Center Quality

- Work Time

- Commuting Time

- Nursing/Lactation

- Psychological Effect
○ Guilt
- Stress Management
○ Employee Loyalty

The findings of this research shed additional light on how to make childcare accessible, practical, and beneficial to mothers as well as the overall population. On-site childcare does impact the markers of influence for mothers, as described by the previous scholarly literature regarding childcare. This can be clearly seen in the themes revealed by this research which are also in alignment and consistent with the reviewed literature. While the broad categories derived from the literature remained the same, the themes gathered show the influence and impact of on-site childcare as well as new findings that are characteristic of on-site care.

\section{Economic Effects}

Cost was noted in the literature review as a factor (Powell, 2002) and influenced by on-site childcare. While cost was still an important aspect to mothers using childcare, on-site childcare provided an exceptionally high level of service for a mainstream price due to the financial support of the organization. This impacted mothers' experience and in some cases decisions with childcare.

\section{Societal Effects}


Networking is a theme that is unique to on-site childcare. Mothers using the onsite centers developed broader networks within the organizations due to their interactions with other employees using the center or employees who had been influenced by the childcare center. It also had a broadening effect on the overall understanding the mothers held about the organization's functioning and operations.

Organizational System Oneness is a theme found that is unique to organizational supported on-site childcare. Due to the systems unity, the culture, norms, standards, values and operation systems of the larger organization manifested in the management and approach within the childcare centers. Mothers using the on-site centers found benefits in the seamlessness of their experience between work and childcare.

The Family/Community Perception theme is noted in the literature and is influenced by on-site childcare. The literature stated that a mother's social circle and family may influence her choices about childcare (Glass \& Riley, 1998) (Pungello \& Kurtz-Costes, 2000). On-site childcare revealed a new dimension. Mothers from traditional communities found greater acceptance in their communities because on-site childcare seemed to allow for more traditional mothering roles with closer proximity to the child. On-site childcare was also an influence in that mothers in some social circles found using the on-site centers to be a status amenity. While using or not using childcare was noted in the literature previously as a status connotation (Shainees, 1980) (Robinson, Rotter \& Wilson, 1982), the status symbol in regards to the style of childcare is new information.

Mothering Style is a theme also influenced by on-site childcare. Physical access to the child allowed for increased daily interactions and immediate connection in the case 
of emergencies. The increased interaction, access, and community of the on-site childcare centers caused the mothers to use the centers as a parent education resource which also influenced mothering styles. The literature noted the importance of support structures (Cardenas, 2005) and the effect workplace policies and work expectations (Stier, 1996) on mothers' childcare determinants. This theme showed that on-site childcare provided necessary support as well as a workplace environment that allowed the mothers to better meet the demands of mothering and work.

\section{Functional Effects}

The Waiting Lists theme is an impact of on-site childcare that is substantiated by the literature. The ability of the organization to provide an environment that allows for child caretaking and for the individual needs of the child to be met are known determinants for mothers concerning childcare (Sylva, Stein, Leach, Barnes \& Malmberg, 2007) (Glass \& Riley, 1998) (Pungello \& Kurtz-Costes, 2000) (Cardenas, 2005). On-site childcare waiting lists impact this because of the need to breast feed the child or for the necessary proximity for customized care. This theme, of on-site childcare Waiting Lists, also impacts the functional needs of the mothers because it is an expected benefit of working for the organization that may not be realized.

Center Quality is a theme that is impacted by on-site childcare. While access to quality childcare is important for women's economic stability and societal equality (Meyers, 1997) (Lifton, 2001), on-site childcare produces a distinctive effect. Due to the support of the organizations, the on-site centers studied were able to create exceptional childcare environments at mainstream pricing. An unanticipated result of this theme is that the excellence of the on-site centers was so esteemed that many of the mothers 
valued this benefit even more than the location of the center. This is especially significant because the importance and value of the location of the center was repeatedly noted by the mothers and shown in the other themes. It can be concluded that quality care is the most fundamental need and concern. After meeting this, subsequent needs can be addressed.

Work Time is a theme influenced by on-site childcare centers. The literature addresses mothers' needs for accommodating workplaces (Glass \& Riley, 1998) (Pungello \& Kurtz-Costes, 2000) (Cardenas, 2005). On-site childcare influences this by aiding in workday efficiency both in terms of mental focus and daily scheduling. The childcare center's operation hours also tended to garner respect from colleagues because it is a branch of the organization. Due to this understanding meetings would be scheduled within the known constraints of the childcare center's hours. However, the onsite centers did not address mothers needing childcare outside of standard business hours regardless of the working demands such as travel, night-shifts, and international meetings that are required by the organization.

Commuting Time is a theme distinctly influenced by on-site childcare. While the literature addresses mothers' concerns with time management needs and access to childcare (Stier, 1996), it does not directly address the impact of commute times as a childcare determinant. Commute times were lessened by on-site childcare. In addition to this, mothers reported that it allowed for a connection and communication time with their children during the commute to the organization. This benefit would not have been realized with childcare near the home or at the beginning of the commute. 
Nursing/Lactation is a theme that was influenced by on-site childcare. Women's concerns with placing infants in childcare (Pungello \& Kurtz-Costes, 2000) were directly impacted. The impact of on-site childcare on lactation was expressed by mothers' preference for breastfeeding over pumping as well as a desire for closer proximity to the child during infancy.

\section{Psychological Effects}

Guilt, as a theme presented in this research, is an idiosyncratic experience generated by on-site childcare. Due to the closeness of the on-site childcare centers to the workplace, some mothers experienced a feeling of guilt for not visiting their children during the workday. The rationale of the mother being that since the childcare was near then she should be able to visit, whereas if the childcare was located further away it would not be possible and the mother not responsible for the lack of interaction with the child during the workday. The literature discusses the importance of self-perception as a determinant, most specifically conflicting feelings about utilizing childcare or practicing traditional home-care mothering (Guendouzi, 2006). The conflicting feelings that generated the literature noted dichotomy of thoughts may also be responsible for generating a re-embodied form of conflicted feelings in the setting of on-site childcare.

Stress Management was a theme influenced prominently by on-site childcare. Immediate access to one's child provided a comfort to the mothers that allowed them to focus on their tasks at work and relieved concern about meeting the child's needs in case of an emergency. Mothers also expressed a sense of increased work-life balance with the integration of family in the working environment. Incorporating these two may address the need some women feel to balance adult engagement with the roles of motherhood 
(Robinson \& Wilson, 1982) (Leach, Barnes, Nichols, Goldin, Stein, Sylva \& Malmberg, 2006).

Employee Loyalty was a theme influenced by on-site childcare. Positive, appreciative employee attitudes about family friendly policies are known (Swoody, 2007). This theme reveals that specifically on-site childcare positively influences the attitudes, about the organization, of mothers using the centers. It also confirms on-site childcare to be a draw and retention mechanism.

Access is the common unifier in these themes. It is the proximity to the child that engenders the primary aspects of the themes. Organizational assistance and support also underlie the themes the interviewees describe because it increases the quality of care. The dual sources, child proximity and organizational support, are the basis for the individual themes noted above.

Close proximity to one's child meets a primary need in the mothers interviewed that increases the quality of their experience with childcare significantly. This can be seen in the themes of Networking, Organizational System Oneness, Family/Community Perception, Mothering Style, Center Quality, Work Time, Commuting Time, Nursing/Lactation, Guilt, Stress Management, and Employee Loyalty.

Organizational assistance and support impacts and overlaps with proximity as a primary theme source. This can be seen in the themes of Cost, Networking, Organizational System Oneness, Waiting List, Center Quality, Work Time, Commuting Time, Nursing/Lactation, Stress Management and Employee Loyalty. The quality of the childcare, which in large part is made possible by the supporting organization, is held in such high regard that in some cases it overcomes the mother's desire for proximity. 


\section{Implications}

The implications of these findings for the mothers using the centers are that onsite childcare does provide a significant advantage to working women, but this benefit can only be realized when the more primary need of high quality childcare has been met. As the research revealed, the drivers of the found themes are proximity and organizational support. These effects can be seen in all of the themes assessed in this research regarding childcare.

The possibility for negative impacts should also not be ignored. While the mothers interviewed for this research had positive experiences with on-site childcare centers, unifying personal and professional worlds may not be the preference for everyone or of benefit. Bringing one's family life in connection with one's professional life may not always be valued. One may feel pressure to uphold family practices to professional levels. If an employee's child is in the same classroom as her manager there could be complicating personal interactions that may crossover into the workplace or vice-versa. The theme of guilt revealed a psychological drawback to on-site childcare that could be a negative for women in using on-site childcare. There are also privacy concerns about family, family planning, emotional situations, and choices that employees wish to shield from the exposure in the workplace. Disclosure of personal concerns in the workplace may not always be desired or beneficial. In order to fully understand the impact of on-site childcare the implications of the benefits as well as the drawbacks must be acknowledged, considered and assessed.

There are also implications for organizations. The overwhelmingly positive impact on employed mothers using the on-site centers benefits the organization in terms 
of employee loyalty, satisfaction, and indications of enhanced employee productivity. Employees using the center may also benefit from increased organizational awareness resulting in a more expansive vision of the organization due to broader employee interactions as noted in theme of Networking. These benefits to the organization may be particularly useful in employment environments where employee retention and attracting high-level talent are vital to the business model as well as in helping to create unified implementation of organizational goals. With many women delaying childbirth after having established careers, it is advantageous for organizations to retain these women at the peak of their productivity and skill sets. In relation to the loss of intellectual knowledge, an organization's investment in on-site childcare is relatively small. Organizations that are not seeking to obtain or retain highly valued employees may not find a benefit to on-site childcare. This may indicate that on-site childcare is not a universally beneficial concept and other incentives or forms of childcare would need to be considered at these.

The research also suggests a benefit to communities that have high quality on-site childcare centers. They may benefit from increased economic stability amongst working women who choose to remain employed after childbirth because of benefits they find in on-site childcare. Additionally, education systems could also be welcoming students who have had increased and beneficial preparation from the high quality on-site centers that increases academic success leading to a future population of contributing community members. Communities may also wish to sponsor or aid childcare centers to produce similar effects or to provide incentives to encourage organizations to sponsor quality onsite or close access childcare. 


\section{Policy Suggestions}

The following suggestions offer possibilities for the application of this research. Some of these policies could be implemented by the organizations and other would require collaborative effort or government sponsorship. The amount of effort, time and resources of the suggestions range from simple, low- cost adjustments to intensive time and monetary investments.

\section{Expectation Management}

The findings of this research can instantly be used to improve the quality of existing on-site childcare centers by implementing a policy that informs mothers that while their presence during the day at the centers is welcomed, it is not and should not be expected. The varying demands as well as varying needs of the child should be the guide when making the choice to visit the center. While the childcare centers may already believe this to be obvious, stating this explicitly may lower the chance of a mother feeling a sense of guilt about daytime visits.

\section{Lowering Wait Lists}

Every organization suffered from waiting lists. In order to meet the needs of the employees and to provide a true benefit the waiting list time must be better managed with greater access to infant care. Access to infant care for lactating mothers is particularly important as well as organizational support during this time. Organizational support could be realized through additional break times for pumping or to nurse at the on-site center throughout the duration of lactation. This would benefit both the employees and well as allow the organization to realize benefits in employee loyalty, satisfaction and retention. 


\section{Review of Research Findings}

While the findings of this research show the current effects and experiences of mother's using the centers, it would be beneficial for organizations providing on-site childcare to review these findings in order to enhance and continue the known benefits or to address areas of concern. A complete copy of this research will be provided to each of the participating organizations as well as a condensed version for rapid review.

\section{On-Site Childcare Fee Adjustments}

Organizations should assess the possibility of implementing a sliding scale fee plan for their on-site centers. The variability in job roles and compensation may result in the exclusion of employees from the on-site centers, which could be considered an employee benefit, because of pricing. A sliding fee scale for the on-site centers would ensure an accessible benefit regardless of position within the organization.

\section{Government Support}

In order to encourage more organizations to incur the expense of supporting an on-site childcare the government should consider extending tax breaks or tax credits to organizations with on-site childcare. There may be qualifying factors for the incentives based on industry, revenue, or employee fees and the percentage of employees using the centers.

\section{Multiple Organization Support}

The findings of this research reveal two central factors to the success of on-site centers to be access and organizational support. Some organizations may not be able to provide the financial support nor the expertise required to begin an on-site childcare center, however a combined effort of businesses in close proximity may realize benefits. 
For example businesses within a corporate park or close urban area could combine resources to begin a childcare center close to the businesses with shared resources. This effort may have a similar impact in benefits that this research found in the examined onsite childcare centers.

\section{Suggested Future Research}

The range of this research produced greater clarity in understanding the influence of on-site childcare on working mothers, but in order to encompass a broader vision of effects on more facets of society further research will be required. The following offers suggestions on how this research could be continued to build on the knowledge provided in this study.

\section{Impact of On-site Centers on Fathers}

While this research was limited in scope to understanding the experience and feelings of mothers using on-site childcare centers, an important continuation of the research should examine the impact on fathers using on-site childcare centers. A study should seek to examine ways in which it affects the fathers' working style, environment, and the parenting style of the fathers. The study should also examine the effect on gender roles. Comparing female and male dominated organizations with gender balanced organizations would also further the understanding in regards to the full impact of on-site childcare.

The study could be conducted in the same manner utilizing qualitative research with phenomenological methods and a similar structure as this research. It would allow 
for a comparison between the two studies. It will also provide a foundation for future quantitative studies that draw on a larger participant pool and that are generalizable.

\section{Effects on Organizations}

Additional research should include an examination of the impacts, costs, and benefits incurred by the organization. The study should include the impact on different types of organizations with varied socio-economic employee demographics. This would increase the understanding of the impact of on-site childcare on varying types of organizations. Combining quantitative and qualitative research methods would allow for a more comprehensive analysis. This topic may need to be divided into several studies. Combining the methods allows for both tangible and intangible findings to be understood. For example, examining topics such as morale and retention rates would require both methods for a full understanding. Partnering with the on-site centers would be beneficial because they often query parents using the center to determine the benefits and deficits of the on-site centers since they do need to justify their expense to the larger organization. Bringing academic research standards to the topic would benefit the organizations, policy development, and parents using the centers by adding to known research.

\section{On-site Center Formation}

Understanding the process of starting an on-site childcare center would be valuable information for organizations and for informing policy. Compiling data through a thorough review of best practices and administrative methods would provide a guide to starting an on-site childcare center. This research could also inform policy by informing government for the creation of incentives and guidelines that assist in the successful 
establishment of an on-site childcare center. Examining failed on-site childcare centers in conjunction would also aid greatly in the understanding of on-site center development. While organizations do visit successful on-site programs to better understand their systems, a formal academic study would create clarity and accuracy around the findings.

Also, a study designed to understand why organizations in similar industries and with similar socio-economic employee bases as those with on-site childcare centers do not begin centers would add to the understanding the formation process of on-site childcare centers.

\section{On-Site Center User Discontinuation}

Research that examines why parents decide to discontinue using on-site childcare would also provide information to inform policy in regards to childcare best practices. The mothers interviewed in this research may have remained at the center because they were pleased with the results. Juxtaposing this with mothers who discontinued use of the on-site centers would serve to provide a broader picture of the impact of on-site childcare. As noted previously, there may be drawbacks such as proximity guilt and privacy that cause parents to have negative experiences with on-site childcare. A study that interviews women who have left on-site childcare would provide a more complete picture of on-site childcare effects.

\section{Feminist Urban Planning \& Feminist Organizational Behavior}

This study of on-site childcare brings together feminist organization and urban planning theories. It accomplishes this by addressing the physical constructs of urban planning as well as the intention of that planning to foster social constructs. Further, it 
studies organizations' employee practices to better understand the effects of family friendly policies.

Primary to feminist urban planning is the development of community. Connection to neighbors and other members of the community eliminates isolation, builds relationships, and forms the basis for empowerment through broader knowledge of the occurrences within the community. As community members unite increased transparency as to the conditions and opportunities afforded within the broader public arise (Wismer, 1999). Eliminating the isolation of women is a key goal with feminist urban planning. Groups that are isolated have limited opportunities for growth and development (Chapple, 2002; Watson, 1999). On-site childcare addresses the need for the development of connections within the community of the work environment.

As organizations consider the role of on-site childcare, feminist ethics and planning must receive greater attention. Feminist ethics are characterized by an emphasis on concepts of responsibility, obligation and care rather than rights, rules and justice which have been the predominate form of male thought (Morgen, 1990). Of particular emphasis is the feminist objective to eliminate oppression and situations which disadvantage individuals. Feminist ethics also seeks to bring qualitative methods and ideas into the space of planning which has largely relied on quantitative measures. Feminist ethics addresses a need to bring moral guidance to planners and act as a bridge between theory and action causing them to consider effects on women and their communities. This would bring a balance between notions of care and concepts of justice, which makes a case for discussion of topics by utilizing inclusive, consensus 
approaches (Hendler, 1994). The measure of on-site childcare success must involve these standards.

A significant benefit of feminist urban planning is that the discipline brings together physical implementation with social constructs. Bringing the two together is vital to creating living spaces that benefit all users, and force planners to look beyond what was once considered private or social concerns into the forefront of spatial, economic, and social planning resulting in public discourse for socio-spatial planning (Milroy, 1991). On-site childcare is an example of this bridge between the physical and social realms. It does this through proximity and enhanced community.

Women's entrance into the labor market has exacerbated incompatibilities between employers and family interests. In many ways this is due to the conflict between paid work and family responsibilities. This conflict is linked to both decreased employee productivity and decreased family functioning (Glass \& Estes, 1997). Through an understanding of work-family incompatibilities societal policies can be developed that ease the tension. This knowledge also empowers organizations to foster workplace atmospheres that are mutually beneficial to women and organizational objectives. Onsite childcare can ease these tensions and pressures to create benefits for women, organizations and society.

Working mothers are an essential segment of the workforce. In order to fully benefit from the expertise offered by these women, reduce turnover, and gain the economic advantages offered by engaged employees, organizations must understand the unique needs, determinants, and inter-role conflicts working mothers' experience. This 
research will shed light on the development of effective family friendly policies through greater understanding of on-site childcare. 


\section{Bibliography}

Bagilhole, Barbara (2006). Family-friendly policies and equal opportunities: a contradiction in terms? British Journal of Guidance \& Counselling, 34(3), p327343.

Baker, Maureen (1992). Family Conflicts: Policy Implications. ERIC Clearinghouse, p17.

Blair-Loy, Mary \& Wharton, Amy S. (2002). Employees' Use of Work-Family Policies and the Workplace Social Context. Social Forces, 80(3), p813-845.

Cardenas, R. (2005). Combining Employment and Breastfeeding: Utilizing a WorkFamily Conflict Framework to Understand Obstacles and Solutions. Journal of Business \& Psychology, 20(1), 31-51.

Chapple, Karen (2002). "I Name It Claim It - In the Name of Jesus, This Job is Mine": Job Search, Networks, and Careers for Low-Income Women. Economic Development Quarterly, 16(4), p294-313.

Davis, A. E., \& Kalleberg, A. L. (2006). Family-friendly organizations? Work and family programs in the 1990s. Work and Occupations, 33(2), 191-223.

Durst, Anne. (2005). Of Women, by Women, and for Women: The Day Nursery Movement in the Progressive-Era United States. Journal of Social History 39(1) 41-59.

Edwards, M-R. (2006). The Role of Husbands' Supportive Communication Practices in the Lives of Employed Mothers. Marriage \& Family Review, 40(4), 23-46.

Fleischer, Jo (1995). Baby boon - On-site daycare helps hold corporate tenants. Fairfield County Business Journal, 34(32), p10.

Frazee, Valerie (1996). Workers are willing to sponsor onsite daycare. Personnel Journal, 75(10), p24.

Gault, B., \& Lovell, V. (2006). The costs and benefits of policies to advance work/life integration. American Behavioral Scientist, 49(9), 1152-1164.

Glass, J. L., \& Estes, S. B. (1997). The family responsive workplace. Annual Review of Sociology, 23, 289-313. 
Glass, J. L., \& Riley, L. (1998). Family responsive policies and employee retention following childbirth. Social Forces, 76(4), 1401-1435.

Guendouzi, J. (2006). "The Guilt Thing”: Balancing Domestic and Professional Roles. Journal of Marriage \& Family, 68(4), 901-909.

Hendler, Sue (1994). Feminist Planning Ethics. Journal of Planning Literature, 9(2), p115-127.

Himmelweit, S., \& Sigala, M. (2004). Choice and the relationship between identities and behaviour for mothers with pre-school children: Some implications for policy from a UK study. Journal of Social Policy, 33, 455-478.

Hjern, A, Haglund B, \& Rasmussen F, Rosen, (2000). Socio-economic differences in daycare arrangements... in Swedish preschool children. Acta Paediatr (Stockholm), p89.

Leach, P., Barnes, J., Nichols, M., Goldin, J., Stein, A., Sylva, K., Malmberg, L-E. (2006). Child Care Before 6 Months of Age: A Qualitative Study of Mothers' Decisions and Feelings About Employment and Non-maternal Care. Wiley InterScience Infant and Child Development, 15, 471-502.

Lehrer, E. \& Nerlove, M. (1986). Female Labor Force Behavior and Fertility in the United States. Annual Review of Sociology, 12, 181-204.

Levin-Epstein, Michael (2001). Childcare Help Still Ranks As Big Benefits Booster. Flexible Benefits, $2, \mathrm{p} 7$.

Lifton, Natasha (2001). Child Care Is a Labor Issue. Social Policy, 31(3), p4.

Mahitivanichcha, Kanya \& Rorrer, Andrea K. (2006). Women's Choices Within Market Constraints: Re-Visioning Access to and Participation in the Superintendency. Educational Administration Quarterly, 42(4), p483-517.

Millward, Lynne J. (2006). The transition to motherhood in an organizational context: An interpretative phenomenological analysis. Journal of Occupational \& Organizational Psychology, 79(3), p315-333.

Milroy, Beth Moore (1991). Taking Stock of Planning, Space, and Gender. Journal of Planning Literature, 6(1), p3-15. 
Montgomery, A-F. (2006). Living in Each Other's Pockets: The Navigation of Social Distances by Middle Class Families in Los Angeles. City \& Community, 5(4) 425-450.

Morgen, Sandra (1990). Challenging the Politics of Exclusion: The Perspective of Feminist Anthropology. Education and Urban Society, 22(4), p393-401.

Meyers, Marcia K (1997). Cracks in the Seams: Durability of Child Care in JOBS Welfare-to-Work Programs. Journal of Family and Economic Issues, 18(4), p379.

Powell, L. M. (2002). Joint labor supply and childcare choice decisions of married mothers. Journal of Human Resources, 37(1), 106-128.

Pungello, E. P., \& Kurtz-Costes, B. (2000). Working women's selection of care for their infants: A prospective study. Family Relations, 49(3), 245-255.

Reilly, T., Entwisle, D., Doering, S. (1987). Socialization into Parenthood: A Longitudinal Study of the Development of Self-evaluations. Journal of Marriage and the Family, 49(May), 295-308.

Robinson, S-L., Rotter, M-F., Wilson, J. (1982). Mothers' Contemporary Career Decisions: Impact on the Family. The Personnel and Guidance Journal, May, 535-538.

Ross-Smith, A. \& Kornberger, M. (2004). Gendered Rationality? A Genealogical Exploration of the Philosophical and Sociological Conceptions of Rationality, Masculinity and Organization. Gender, Work \& Organization, 11(3), p280-305.

Shainees, N. (1980). The Working Wife and Mother - a "New" Woman? American Journal of Psychotherapy, July(3), 374-386.

Stier, H. (1996a). Continuity and change in women's occupations following first childbirth. Social Science Quarterly, 77(1), 60-75.

Stier, H. (1996b). Coupled careers: The effect of spouse's resources on success at work Bernasco,W. European Sociological Review, 12(2), 210-212. 
Stier, H., Lewin-Epstein, N., \& Braun, M. (2001). Welfare regimes, family-supportive policies, and women's employment along the life-course. American Journal of Sociology, 106(6), 1731-1760.

Swody, C. \& Powell, G. (2007). Determinants of Employee Participation in Organizations' Family-friendly Programs: A Multi-level Approach. Journal of Business \& Psychology, 22(2), p111-122.

Sylva, K., Stein, A., Leach, P., Barnes, J., Malmberg, L-E., (2007). Family and child factors related to the use of non-maternal infant care: An English study. Early Childhood Research Quarterly, 22 (1), 118-136.

Watson, Sophie (2000). Bodies, gender, cities.

City, 4(1), p101-105.

Wismer, Susan (1999). From the Group Up: Quality of Life Indicators and Sustainable Community Development. Feminist Economics, 5(2), p109-114. 


\section{Appendix A - On-Site Directors Interview Questions}

How many children are at this facility on a given day?

What is the ratio of children who are in the facility part-time to full-time?

Is the facility only open to employees of the organization?

Tell me about the process of accepting a child at this facility.

Is there a waiting list?

Tell me about running an on-site childcare facility.

Have you worked at off-site centers? What is similar and what is different?

Who do you report to in the organization?

Do you know if the childcare center fits into the organization's strategic plan?

What type of interaction do you have with parents?

What kinds of comments do you hear from parents about the center and the organization?

What experience does an on-site childcare center offer?

Do you have additional thoughts about on-site childcare? 


\section{Appendix B - Teachers/Caretakers Interview Questions}

What do you do in your role as a teacher/caretaker?

What type of interaction do you have with parents?

What kinds of comments do you hear from parents?

What experience does an on-site childcare center offer to both the children and the parents?

Do you have additional thoughts about on-site childcare? 


\section{Appendix C - Mothers Interview Questions}

What is your job at the organization?

Are you a single parent?

How many children do you have?

How many children do you have at the on-site center?

How old are your child/children? Did access to on-site childcare effect the age you put your child in care?

How long have you been using the on-site childcare center?

Is your child there full-time or part-time?

(If more than one child - but one is not in childcare) Did you put your first child in childcare? If not, did on-site childcare impact your decision to place the second child in childcare?

Did you have to wait to have your child placed in the center? How long?

What were some of the reasons you chose to work there? Was on-site childcare a determinant?

Did access to on-site childcare impact your decision to return to work?

Did access to on-site childcare impact your decision of when to return to work?

What has been your experience with on-site childcare?

What has the situation been in regards to scheduling? (work schedule, schedule with spouse/partner, home schedule, other childcare options) 
Were there financial factors in deciding to use childcare? Did on-site childcare play a role in this?

Do you know how on-site childcare compares, financially, with other childcare options? Was this a factor in your decision to use on-site childcare?

What role has on-site childcare played in your workplace experience?

Does on-site childcare influence the amount of time you work?

What role does on-site childcare play in your support network?

What do your friends/family think about you using on-site childcare?

Have you developed an enhanced social or support network within your organization because of your use of on-site childcare?

What effect does on-site childcare have on your mothering style? Are you more available to your child?

Does on-site childcare increase your access during work hours to your child? If so, how do you feel about this?

Does on-site childcare impact your ability to meet your child's needs?

Does on-site childcare have an impact on your child?

Does working for an organization with on-site childcare offer special considerations or flexibility? What does this look like for you?

Did on-site childcare alter the age you placed your child in childcare?

What other options would you consider if on-site childcare was not an option?

Do you have additional thoughts about on-site childcare? 


\section{Appendix D - Analysis Example}

The following provides a simplified example of the analysis process. The process is accomplished through multiple pass stages/readings from all of the interviews. The purpose is to find commonalities and account for any outliers. Each "pass" provides increasingly refined assessment, until a "theme label" is determined. Further refinements in the themes may occur later in the process if themes need to be combined or split based on final analysis.

- PASS ONE: Generally noting ideas and thoughts.

- PASS TWO: Further analysis with support from other interview reviews.

- PASS THREE: Giving the code a formal name to be used as a theme.

\section{Transcription from interview:}

R: How does the scheduling work for you?

M: The biggest benefit is the close to drop offs. My friends have to drive a $1 / 2$ hour each way to drop of their children at daycare. That is something I never think of. I am so grateful for that. I can't image adding another $1 / 2$ hour to my work day before and after. [PASS ONE: Time management with pick-up and drop off.] [PASS TWO: Less driving.] [PASS THREE: COMMUTE TIME]

R: Do you think that is part of the reason why you chose to stay here?

M: Oh definitely. They call it handcuffs at the CDC; because once you get your kid in there it is so easy and convenient that you can't.... I actually did have an interview at (another company) two or three years ago and I would have done, well if I didn't have my daughter I would have taken the job just for the variety cause they were only offering a few thousand dollars more than here, but I kind of figured I needed $\$ 10,000$ to make the move and deal with the daycare and the change. So it did keep me here.

[PASS ONE: Employee benefit of on-site center retains employees.] [PASS TWO: Increases commitment of employees using childcare center.] [PASS THREE: EMPLOYEE LOYALTY] 


\section{Appendix E - Analysis Process Diagram}

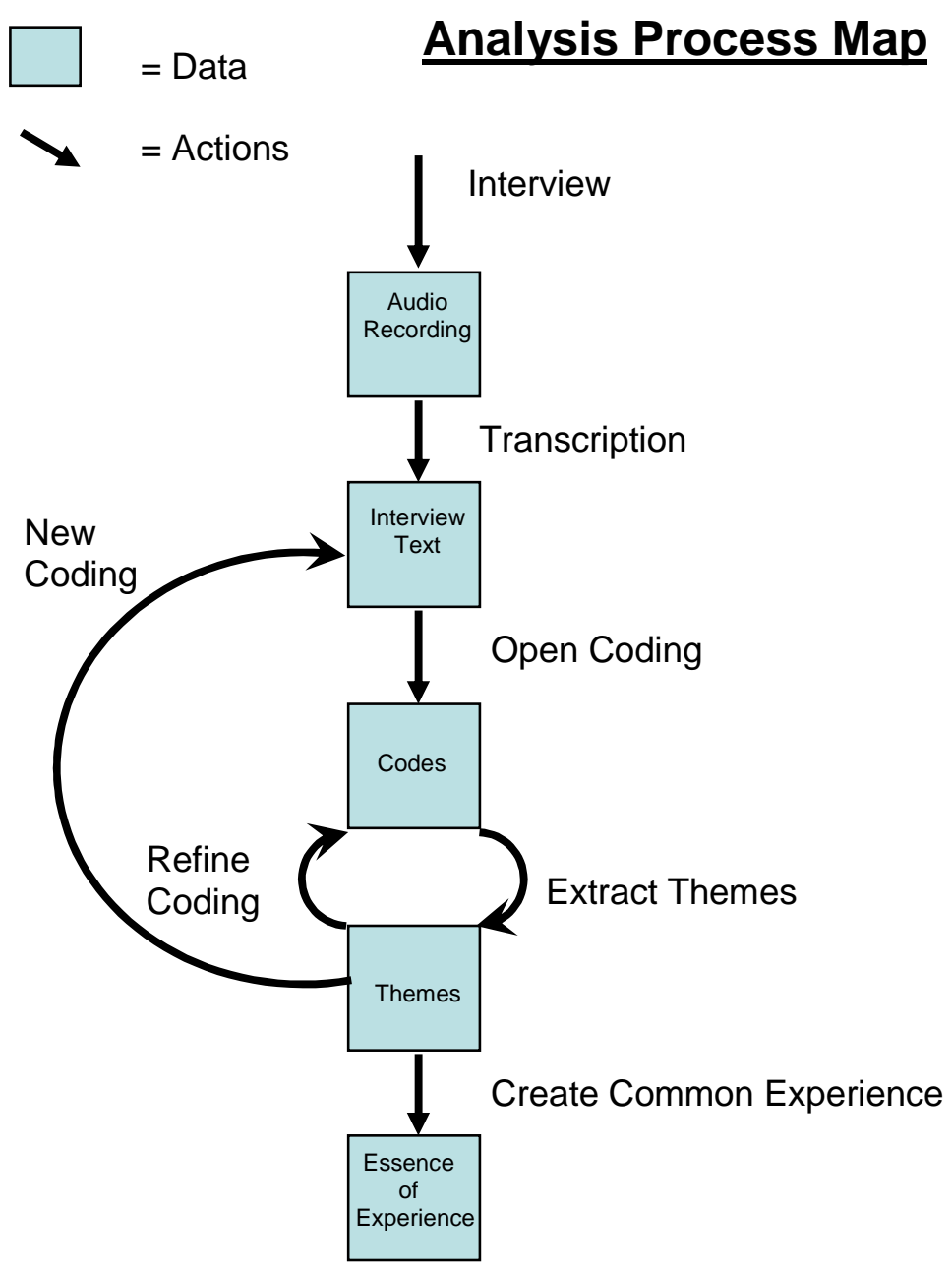




\section{Appendix F - Human Subjects Review Application}

The human subjects review application consisted of a brief overview of the problem and research methods. It also provided context in regards to the benefits the findings may provide, including furthering the known literature and societal benefits. The application

continued by providing information about the subject recruitment process of snowballing, the types of participants and the industries from which the participants would be recruited.

An informed consent form was presented in the application to be given to each participant for review and signature. The consent form outlined the participants' rights and protections due. Signed copies were stored in a file with the contact information that was separate from the interview information.

A first-person scenario was developed for the application to ensure that the researcher had awareness as to the process and responses that a participant may experience. The exercise allowed the researcher to rehearse a possible reaction to being contacted and participating in the research.

The application also included precautions and procedures to safeguard the participants from potential risks. The primary focus of these safeguards was on emotional sensitivity that valued and honored the participants' situations and experience contributions. Safeguards for the participants' records and information were also taken to ensure privacy. 